University of New Haven

University of

New Haven

Digital Commons@ New Haven

$9-2013$

\title{
Response of an Arch Dam to Non-Uniform Excitation Generated by a Seismic Wave Scattering Model
}

\author{
Reza Tarinejad \\ University of Tabriz \\ Rouzbeh Fatehi Shomeh \\ University of Western Ontario \\ Ronald S. Harichandran \\ University of New Haven, rharichandran@newhaven.edu
}

Follow this and additional works at: http://digitalcommons.newhaven.edu/civilengineering-facpubs Part of the Civil Engineering Commons

\section{Publisher Citation}

Tarinejad, R., Fatehi, R., and Harichandran, R. S. (2013). "Response of an arch dam to non-uniform excitation generated by a seismic wave scattering model." Soil Dynamics and Earthquake Engineering, 52, 40-54. doi:10.1016/j.soildyn.2013.04.011

\section{Comments}

This is the authors' accepted version of the article published in Soil Dynamics and Earthquake Engineering. The final version can be found in the ASCE library at http://dx.doi.org/10.1016/j.soildyn.2013.04.011 


\title{
Response of an Arch Dam to Non-Uniform Excitation Generated by a Seismic Wave Scattering Model
}

\author{
Reza Tarinejad ${ }^{\mathrm{a}}$, Roozbeh Fatehi ${ }^{\mathrm{a}}$, and Ronald S. Harichandran ${ }^{\mathrm{b} *}$ \\ ${ }^{a}$ Faculty of Civil Engineering, University of Tabriz, Tabriz, East Azerbaijan Province, Iran \\ ${ }^{\mathrm{b}}$ Tagliatela College of Engineering, University of New Haven, New Haven, USA
}

\begin{abstract}
Non-uniform ground motions are generated based on a single record available at a site and seismic wave scattering analysis. The Chino Hills 2008 earthquake records at the Pacoima Dam site are used to indicate the accuracy of the method. Dynamic analysis of the Pacoima dam-reservoir-foundation under uniform and non-uniform ground motions is carried out using the EACD-3D2008 software, and the results are compared to recorded responses at different locations on the dam. There is good agreement between computed and recorded displacements of the dam for non-uniform excitation. For uniform excitation, the displacements are underestimated in comparison with those obtained from recorded excitation. Significant intensification of stresses, especially near the foundation, and different patterns of stress distribution are observed for non-uniform excitation in comparison with uniform excitation. For uniform excitation maximum stresses occur in the crown cantilever near the crest, but for non-uniform excitation the maximum stresses occur along the sides and near the foundation.
\end{abstract}

Key words: Non-uniform ground motion, EACD3D-2008, Arch dam, Chino Hills 2008 Earthquake, Pacoima dam

\section{Introduction}

Investigation and research on dams is important because of the high costs of their construction and maintenance, severity of damages caused by failure, and their crucial role in supporting development of communities. Considerable advances have been made in recent decades on the different factors influencing the behavior of dams in order to develop more reliable analysis and design methods. Among these factors, earthquake induced motions are of great importance for dams located in seismic zones due to the complexity and intensity of induced forces and their unpredictable nature. In the conventional seismic analysis of structures, uniform free-field ground motions are applied as input excitations at supports. However, investigations on the seismic response of large and extended structures like dams, bridges, pipelines and power plants indicate that major variations in the amplitude and phase of excitations can occur at distant supports and along abutments during an earthquake. Different arrival times of incident seismic waves at different locations on the surface (wave passage effect), and modification of waveforms and direction of propagation due to scattering by various rock layers in the path (site effect) are known to cause spatial variation of ground motion. In addition, reflections and 
refractions of seismic waves by topographic irregularities can cause amplifications and de-amplifications of motions along ridges and canyons (e.g., Coyote Lake Dam [1], Mauvoisin Dam [2, 3], Fei-Tsui Dam [4]). Large amplitudes of accelerations due to topographic amplification effect caused damages and opening of joints at the Pacoima Dam during the 1971 San Fernando and 1994 Northridge earthquakes [5, 6]. This phenomenon was also observed during the 2001 San Fernando earthquake at the Pacoima Dam site [7]. Non-uniform motions at different support locations of a structure may cause larger and different stress responses compared to uniform support excitation and should be accounted for. However, due to the complexity of this type of analysis and the unavailability of excitation data at different support locations, analysis that includes spatially non-uniform excitation is usually not performed. Methods of artificially generating spatially varying ground motions from limited recorded data a site have been developed over recent years [8], but these typically do not apply to sites with complex topographies.

In most simulation methods, correlations of motions at different supports are interpreted using the "coherency function". Researchers have proposed various coherency functions [8-16]. The wave passage and site condition effects and their correlation are included in some coherency models. Many researchers have investigated the random vibration response of dams to non-uniform excitation [17-21]. However, due to the simplifying assumptions, random vibration analysis cannot be readily applied when significant variations of motion due to topographic effects occur.

Most investigations on the reflection and refraction of seismic waves due to topographic features are conducted using 2D or simple 3D models that assume a prismatic canyon, with specific hypothetical wave incidence angles. The effects of interaction of various wave types are often neglected (e.g., P, SH or SV waves are considered separately). Therefore, results of these studies are usually not comprehensive enough to be used in place of or compared with data from real events. The results of single-wave scattering analysis have been used in some investigations to generate non-uniform ground motions along canyon abutments and examine the effects of non-uniform excitation on the response of dams [22-31]. These studies suggest that the stress response due to non-uniform excitation on the dam body is profoundly different from the response due to uniform excitation. The primary reason for this is the quasistatic response induced by non-uniform excitation, which causes intense stresses on the dam body near abutments and can be larger than stresses caused by inertial forces. The contribution of the quasi-static response to the total response depends on the rate of variation of motions along the abutments. The results demonstrate the necessity of including non-uniform excitation in the analysis.

In 2005, Alves and Hall [32] conducted a study on the effects of non-uniform excitation on the dynamic response of the Pacoima Dam using a different approach. They proposed interpolating a non-uniform ground motion time series using frequency transfer functions of available data including amplification and time delay of motions assuming vertical propagation of seismic waves. In this method, one record at the base and one record at each side of the canyon are required to simulate the variation of motions along abutments. The agreement of structural response results with recorded data during the 2001 San Fernando earthquake using this algorithm was excellent but the requirement of multiple recorded data at the site is restrictive since such records are often unavailable. This method also cannot generally be used to solve the problem of simulation of motions at a dam canyon. Wang and Chopra [33] extended the EACD3D2008 program based on previous versions to consider non-uniform base excitations. The performance of the program was evaluated by analyzing the response of the Pacoima Dam and Mauvoisin Dam during the 2001 San Fernando and 1996 Valpelline earthquakes. The procedure presented by Alves and Hall was 
used to interpolate the variation of ground motions along abutments. Agreement of the response results for the Mauvoisin Dam during the Valpelline earthquake with recorded data was not as good as the results of the Pacoima Dam during the 2001 San Fernando earthquake, possibly because of the inefficiency of the ground motions generation procedure.

Despite all the efforts during recent years, simulation of the variation of ground motions along canyon abutments remains a fundamental problem preventing the analysis of dams to non-uniform excitations. In this work, an algorithm based on seismic wave scattering analysis of an arbitrary shaped canyon is used to generate motions along dam abutments. The TDASC computer program was developed utilizing a 3D boundary element method to evaluate the site response. The procedure has three significant features: the capability of accounting for realistic canyon geometry; the ability to consider the simultaneous effects of different types of seismic waves; and the capability to simulate ground motions at any arbitrary point of the canyon topography from one single record at any location of the site [34-35].

In this research, the efficiency and accuracy of the algorithm and the effects of non-uniform excitation on the dynamic response of the Pacoima Dam during the 2008 Chino Hills earthquake are studied. First, the results of the ground motion simulation procedure are compared with recorded data. The non-uniform and uniform excitation responses of the dam are evaluated based on the generated ground motions. The EACD-3D2008 program was used to estimate the dynamic response of the dam. Dam-foundationreservoir interaction, water compressibility and partial wave absorption of the reservoir bottom effects were taken into account. A comprehensive system identification study was performed to calibrate the dam-foundation-reservoir system model. The acceleration and displacement responses of the dam to uniform and non-uniform excitation are compared to the corresponding recorded responses during the earthquake; also stresses on the dam body from both cases are evaluated and discussed. The differences and the influencing factors are presented and discussed in the following sections.

\section{Ground Motion Generation Method}

The seismic response of the dam site (in the absence of the dam) obtained from wave scattering analysis in an arbitrary $3 \mathrm{D}$ shaped canyon model was used to generate ground motions. The arbitrary direction of any incident wave is defined by two angles, $\theta_{h}$ and $\theta_{v}$, corresponding to the direction of the normal to the wave front with the horizontal $x$ - and the vertical $z$-axes respectively (see Figure1).The canyon rock is assumed to have homogeneous, isotropic and linear material properties. The propagation direction is assumed to be identical for all wave types and the effects of surface waves are neglected. The main problem is to determine the incident angle of seismic waves. If the causative fault location is available, the horizontal incident angle of the waves can be assumed approximately as the angle between the canyon axis and the line connecting the epicenter of the earthquake to the site. To determine the vertical incident angle, a trial and error process based on numerical analysis was used to acquire the appropriate angle that led to a reasonable agreement between observed and generated ground motions. In the process, the frequency transfer functions (TF) of arbitrary points on the canyon, corresponding to a specific type of wave and hypothetical vertical incident angle, were estimated by numerical analysis. Simultaneous interaction of different wave types were considered by using contribution factors $(0 \sim 1)$ in the form of $(\alpha$ $\left.T F_{S H \text { wave }}+\beta T F_{S V \text { wave }}\right)$ to obtain the final transfer functions. The final transfer functions were then 
compared with transfer functions of the recorded data. Once the proper vertical incident angle was achieved, motions at arbitrary points were generated by multiplying the corresponding normalized final transfer functions by the Fourier transform of a given record at the reference point. The feasibility and uniqueness of the solution from this trial and error process was demonstrated by an inverse problem before application of the method to the present research $[34,35]$.

\section{Case Study}

\subsection{Pacoima Dam}

The Pacoima dam, a 113m high moderately thick concrete arch dam, located in N34.334 W118.396 in Southern California was chosen for the case study because it has a seismometer array of 17 accelerometers installed at different elevations on the body and abutments of the dam (see Figure 2), and a diverse set of earthquake events have been recorded there. The rather homogenous property of its foundation rock also satisfies the assumptions made in this research.

\subsection{July 2008 Chino Hills earthquake}

The 2008 Chino Hills earthquake occurred $82 \mathrm{~km}$ away from the dam at N33.96 W117.76 with a focal depth of $13.7 \mathrm{~km}$. It was selected for the case study since the observed motions at the dam during the earthquake were small enough to satisfy the linear material property assumptions of the concrete and foundation rock assumed in the analyses. Also, the hypocenter of the earthquake was far enough from the dam site so that the seismic waves could be assumed to propagate in an identical direction with respect to the canyon axis and the effects of surface waves could be neglected. The location of the earthquake epicenter and distribution of motion intensity are illustrated in Figure3.

Figure 4 illustrates the stream direction $(E-W)$ time histories of recorded accelerations at the base and abutment channels during the earthquake. The first $10 \mathrm{sec}$ durations of the records were ignored to reduce the analysis time. Therefore, the zero time in the diagrams in the figures corresponds to the $10^{\text {th }}$ second in real data. The essential parameters of the records are presented in Table1. The mean period is a simplified parameter that represents the dominant frequency through:

$$
T_{m}=\frac{\sum\left(\frac{A_{i}^{2}}{\omega_{i}}\right)}{\sum A_{i}^{2}}
$$

where $A_{i}$ are the Fourier amplitudes of the excitation and $\omega_{i}$ are the discrete Fourier transform frequencies. Figure 5 shows the Fourier amplitudes of the stream component of the recorded accelerations at the abutment channels and at the base. The amplification of accelerations and time lag between motions at different elevations are revealed in Figures 4 and 5 and Table 1. Intensification of higher frequencies and shortening of dominant wavelengths due to site effects are noteworthy when comparing the frequency content of the base and abutment records. This phenomenon can also be described with the concept of the mean period in Table1. Intensification of higher frequencies would increase the contribution of higher 
vibration modes in the structure's response and therefore consideration of more vibration modes might be necessary to obtain accurate results of the dam response.

\section{Simulation of earthquake ground motions}

Accelerations along the canyon abutments were generated by multiplying the normalized transfer functions (obtained from numerical analysis) by Fourier transforms of the base accelerations and are compared to the Fourier transformsof recorded acceleration during the earthquake. To validate the numerical results, normalized transfer functions of the abutment records were used as target transfer functions. Target transfer functions were estimated by dividing the Fourier transform of the abutment records by that of the base record. However, the division results in irrational values and high variations over some frequencies because some non-zero amplitudes of Fourier transforms at the abutments originate from approximately zero values at the base because of the scattering and reflection of seismic waves by the canyon. One approach to obtaining reasonable frequency transfer functions that smoothen the results is to use the ratio of the acceleration response spectra instead of the Fourier transforms. Using velocity or displacement response spectra should reveal similar results. Figure 6 illustrates the ratio of acceleration response spectra of the records along the abutments to the base which are used as the normalized transform functions. Increasing the damping makes the functions smoother but decreases the accuracy especially for higher frequencies. The selection of appropriate spectral damping depends on judgment and excitation properties. A spectral damping of $2 \%$ was found to be appropriate for the 2008 Chino Hills earthquake and the corresponding transfer functions were selected as target functions. The amplification pattern is quite different in the left and right abutments and for different components.

\subsection{Modeling of Pacoima dam site}

Analysis of the Pacoima dam site using a uniform canyon model, with the dam-foundation interface considered as a uniform cross section, revealed highly inconsistent results with recorded data in all trialand error steps. This was due to the sensitivity of seismic wave scattering analysis arising from the extremely complex geometry of the Pacoima canyon and its significant difference from the uniform model. This difficulty of prediction demonstrates the necessity for realistic modeling of site topography. Further efforts were made to improve the prediction results by adjusting the model to be more representative of the topographic information of the canyon. Figure 7 illustrates a rather realistic boundary element model of the canyon including 220 boundary elements. The ground motions were assumed to be uniform over the thickness of the dam body and hence the dam-foundation interface was assumed to be in a plane. Studies indicated that a model with dimensions of 8 and 4 times of the canyon depth in the stream and cross-stream directions, respectively, was adequate to obtain reasonable precision. According to the frequency content of the excitation and natural vibration frequencies of the dam (e.g., the $20^{\text {th }}$ natural frequency of the dam is $18.78 \mathrm{~Hz}$ ), the seismic wave scattering analysis was conducted in the frequency range of $0 \sim 125 \mathrm{rad} / \mathrm{s}$ with $1.25 \mathrm{rad} / \mathrm{s}$ steps. The variations of the frequency response results between consecutive steps were quite smooth and hence the results for intermediate frequencies were calculated using linear interpolation. For frequencies higher than $125 \mathrm{rad} / \mathrm{s}$ an amplification factor of 1.0 
was applied, since these frequencies had a negligible effect on the structure's response. The boundary elements should have a maximum length of $1 / 4$ the minimum excitation wavelength for accurate evaluation of the effects of incident waves. The maximum length of the elements used was $15 \mathrm{~m}$, which was adequate for the frequency range considered.

Based on previous in situ and system identification investigations [7, 36], a Young's modulus of $12.1 \mathrm{GPa}$, damping ratio of $4 \%$, and a Poisson's ratio of 0.25 were used for the foundation rock. Site investigations suggested densities that yielded a shear wave velocity between 1500 and $2500 \mathrm{~m} / \mathrm{s}$ for the foundation rock. A shear wave velocity of $2000 \mathrm{~m} / \mathrm{s}$ yielded reasonable results and was the median value for the given range. Also, an estimation of the seismic wave velocity based on the time between the $P$ wave dominant and $\mathrm{S}$ wave dominant portions of the records suggested a similar value.

\subsection{Incidence angle trial and error process}

According to the epicenter of the earthquake and location of the dam site, the horizontal angle of wave incidence, $\theta_{h}$ (see Figure 1), was estimated to be approximately $30^{\circ}$ with respect to the canyon axis (stream direction, $E-W$ ), and the vertical incidence angle $\theta_{v}$ was varied from $0 \sim 90^{\circ}$ in $20^{\circ}$ increments to find the best agreement between the analysis results and recorded data. Thus, analyses were conducted assuming $\theta_{H}=30^{\circ}$ and $\theta_{V}=0^{\circ}, 20^{\circ}, 40^{\circ}, 60^{\circ}, 80^{\circ}$ for $S H$ and $S V$ waves. For each set of incidence angles, the results of the two shear waves were combined together with various contribution factors to obtain transfer functions that were compared to the target functions. Through all these trial and error steps the transfer functions corresponding to $\theta_{H}=30^{\circ}$ and $\theta_{V}=80^{\circ}$ with contribution factors of 0.60 for the $S H$ wave and 0.40 for the $S V$ wave yielded the best agreement with the target transfer functions for the 2008 earthquake records.

\subsection{Generation of ground motions}

The final transfer functions were calculated for all nodes along the canyon walls using the trial and error process. The time series of accelerations were evaluated by multiplying these transfer functions by the Fourier transform of the base records and estimating the inverse Fourier transform of the results. To eliminate errors due to the forward and inverse Fourier transformations and to assure that the resultant velocity and displacement time series oscillate around zero, the generated accelerations were band-pass filtered using a 5-pole Butterworth filter with a $0.1 \mathrm{~Hz}$ high-pass and $50 \mathrm{~Hz}$ low-pass filter and were baseline corrected using the linear polynomial method. The time lag between ground motions due to waves traveling along the canyon had not been taken into account in the seismic wave scattering analysis. Accurate prediction of the time lag between motions at different locations along a canyon is a challenging task because of the complex pattern of wave propagation caused by various reflections and refractions. The time delay estimated according to the relative distance of the points from the base point assuming an upward constant wave propagation velocity $\left(C_{s}=2000 \mathrm{~m} / \mathrm{s}\right)$, was applied to the generated accelerations.

Figures 8 and 9 show the agreement between the generated acceleration time histories at the abutments with corresponding records. Figure 10 shows a comparison between the generated response spectrum using a $2 \%$ damping ratio and recorded data. 
Comparison of numerical results with the recorded data indicates excellent agreement for the stream component $(E-W)$ of accelerations in all frequency ranges. The consistency is generally fair for the crossstream and vertical components with good accuracy for low frequencies. Figures11 and 12 show the good agreement of displacements at both abutments estimated from generated and recorded accelerations for different displacement components. The average error of the simulated accelerations compared to the recorded accelerations is less than $20 \%$. For the two time periods around 15 and $17.5 \mathrm{sec}$ in the stream component of displacement at the south abutment, the average error of the estimated displacements is less than $10 \%$.The larger error in this particular result might be a result of previous damages and subsequent rehabilitation of the dam. Some discrepancies between recorded and computed results may be due to the following reasons: (1) In the numerical model the records were treated as free-field data while the actual records likely included dam-foundation-reservoir interaction effects during the earthquake; (2) The stiffness of the dam, its weight and dam-foundation-reservoir interaction may significantly affect the canyon's seismic response for both the cross-stream and vertical components, but have relatively minor effects on the stream component of the responses; (3) The assumptions of homogenous, isotropic and linear behavior of the bedrock, neglecting the effects of compression and surface waves and assuming a single wave incidence angle may be an over-simplification. However, the results are satisfactory because the stream component has the most significant effect on the seismic response of an arch dam and the accuracy of the results for the cross-stream and vertical components is reasonable in the range of dominant response frequencies of the dam.

Generally, considering the inherent complexities of the problem, the frequency content of the accelerations is very well simulated in the stream components and over a substantial frequency range forthe other components. The generated accelerations are satisfactory for reliable evaluation of the seismic response of the dam.

Figure 13 depicts the time series of generated accelerations for the stream-direction component at different elevations along the south abutment of the canyon. Similar sets of data for other acceleration components and for the other side of the canyon were also generated in order to conduct non-uniform seismic analysis of the dam and to evaluate the applicability and accuracy of the generated motions. The results are presented and discussed in the following section.

\section{Seismic response of Pacoima Dam during the 2008 Chino Hills earthquake}

The dam-foundation-reservoir system analysis was carried out using EACD-3D 2008. The dam body was modeled using 110 shell finite elements. The concrete dam body was assumed to be homogenous, isotropic and linear elastic. The dam-foundation interface was modeled using 26 boundary elements. The foundation rock was assumed to be homogenous, isotropic and viscoelastic.

The motions were sufficiently small that water level variations would not significantly affect the dam's response. The water level during the earthquake was assumed to be 40 meters below the crest, a level reported during a forced vibration test in July 2002 [36] (The 2008 earthquake also occurred in July). A pressure wave velocity of $1438 \mathrm{~m} / \mathrm{sec}$ and unit weight of $9.8 \mathrm{kN} / \mathrm{m}^{3}$ was assumed for the impounded water. The absorptiveness of reservoir bottom and sides due to sedimentary materials was taken into account by assuming a wave reflection coefficient of 0.5 . 
System identification investigation of the dynamic behavior of the Pacoima dam during the 2008 earthquake was performed using the Auto Regressive with exgenous excitation (ARX) method for calibration of the numerical model [37]. The results are compared to the results of previous investigations and forced vibration tests [36]. To consider the effects of spatial variation of ground motions on the structural response, multiple-input single-output (MISO) models were applied instead of single-input single-output (SISO) models. Time variations of modal parameters of the dam were determined by time windowing of the earthquake records. Using the whole duration data of the 2008 Chino Hills earthquake, frequencies of the first symmetric and anti-symmetric modes of the dam were identified as $5.45 \mathrm{~Hz}$ and $5.65 \mathrm{~Hz}$, respectively [37], which are in good agreement with the 2002 forced vibration test results of 5.35-5.45 and 5.65-5.75 Hz, respectively [36]. System identification of the dam using "before the main shock", "main shock" and "after the main shock" portions of the accelerations and also, non-overlapping $10 \mathrm{sec}$ windows of the records, indicated that no considerable variations of modal properties occurred during the earthquake. Thus, the response of the dam to the earthquake motions was essentially linear [37].

Young's moduli of $24.3 \mathrm{GPa}$ for concrete and $12.1 \mathrm{GPa}$ for rock, unit weights of $22.3 \mathrm{kN} / \mathrm{m}^{3}$ for concrete and $25.9 \mathrm{kN} / \mathrm{m}^{3}$ for rock, Poisson's ratios of 0.2 for concrete and 0.25 for rock and $2 \%$ viscous damping in all natural vibration modes for concrete and $4 \%$ for rock, which are all in the range of previous site investigation reports $[7,36]$, were selected for analysis. The frequencies of the first symmetric and antisymmetric modes computed through modal analysis were $5.43 \mathrm{~Hz}$ and $5.6 \mathrm{~Hz}$, respectively, and are in good agreement with the results of $5.45 \mathrm{~Hz}$ and $5.65 \mathrm{~Hz}$ obtained from system identification using real records [37].

The first 20 natural vibration modes were used to compute the response of the dam. Generated ground motions along the canyon and recorded data at the dam base were provided as non-uniform and uniform seismic excitations in the analysis, respectively. The finite element model of the dam-foundation-reservoir and arrangement of the installed accelerometers are shown in Figure14.

The displacement results for uniform and non-uniform analysis and the corresponding recorded responses during the earthquake at the crest levelareshown in Figures 15 to 17. Unfortunately, the Channel 2 recording (radial record at crest center) is not available for comparison of the results. There is good agreement between the computed and recorded displacements for the different components of nonuniform excitation. On the other hand, for uniform excitation the results are under estimated with respect to the displacements obtained from records.

The acceleration records at the crest level and the corresponding computed accelerations due to uniform and non-uniform excitations are shown in Figures 18 to 20. The maximum acceleration responses are underestimated in uniform analysis, and slightly overestimated in non-uniform analysis. The estimated radial displacement and acceleration of the crest center due to uniform excitation is $25 \%$ and $40 \%$ less than the corresponding responses estimated from records and indicate that assuming uniform excitation is unconservative. On average, the maximum acceleration of different components was overestimated by $15 \%$ when non-uniform analysis was used and underestimated by $40 \%$ when uniform analysis was used. Overestimation of the acceleration response in non-uniform analysis could be due to the assumption of linear material properties and the slight differences between recorded and generated excitations. However, the responses are very well simulated over time in non-uniform analysis, and the maximum 
acceleration and displacement responses alone should perhaps not be used to validate the results. The response spectra of accelerations due to recorded and generated motions were computed and compared for a better understanding of the agreement of the results in the frequency domain. Figure 21 shows the comparison between the $2 \%$ damped acceleration response spectra based on recorded and computed accelerations and indicates that the frequency content of the response is very well simulated in nonuniform analysis. On the other hand, the responses due to uniform excitation are very much underestimated and their frequency content is quite different from the real records. The assumption of linear elastic behavior for concrete and rock materials, and a uniform cross section for the canyon in the EACD-3D2008 computer program are likely the main reasons for some of the discrepancies. Following the damages caused by the San Fernando and Northridge earthquakes to the dam (opening of joints near the thrust block at the left abutment and severe fracturing of the rock mass at the upper left abutment), the dam was rehabilitated. The effects of the fractured rock and the reinforcements made at the upper left abutment were not considered in the generation of ground motions. Some nonlinearity induced by these defects may explain more of the discrepancy in the computed response spectra the left abutment records (Channels 5 and 8) compared to the right abutment records (Channels 1 and 6) in Figure 21. Comparing the frequency content of the records with the computed response demonstrates that the dominant response period was lengthened at the left abutment due to previous rock mass damage.

The results indicate that major portions of the dam's response to the 2008 earthquake was due to the quasi-static response, which means that the spatial variation of ground motion would significantly affect the structure's response to the earthquake. The quasi-static component is the part of the response in nonuniform excitation computed when inertia and damping effects are neglected (i.e., dynamic effects are not present and the structural response can be estimated statically). The quasi-static component under uniform excitation induces uniform displacements at all foundation nodes, and the dam moves as a rigid body inducing no stresses. For non-uniform excitation, the difference between displacements at foundation nodes causes stresses, especially at locations near the foundation. The contribution of the quasi-static response to the total response depends on the excitation and structural characteristics. The ratio of quasistatic response to the total response during the 2008 earthquake at channels 2, 3 and 4 (crest center radial, vertical and tangential) were $63 \%, 96 \%$ and $95 \%$, respectively, while these ratios were estimated to be $45 \%, 90 \%$ and $78 \%$ during the 2001 earthquake, and $87 \%, 97 \%$ and $93 \%$ during the Northridge earthquake (Chopra and Wang [3]). The quasi-static response is greater for the cross-stream and vertical components compared to the stream direction component. The dynamic response becomes more dominant at regions near the crest for the stream component. The envelope of the tensile arch and cantilever stresses on the upstream and downstream faces of the dam due to uniform and non-uniform excitations are shown in Figures 22 and 23. The ratio of arch tensile stresses from non-uniform and uniform excitations for the central and foundation parts of the dam body are 2.1 and 3.5, respectively. The ratio of cantilever tensile stresses from non-uniform and uniform excitation for the central and foundation parts of the dam body are 2.4 and 3.8, respectively. Significant intensification of stresses, especially near the foundation, and different patterns of stress distribution are obtained for non-uniform excitation in comparison with uniform excitation. For uniform excitation maximum stresses occur in the crown cantilevernear the crest, but for non-uniform excitationmaximum stresses are concentrated at the sides and near the foundation. A stress concentration region near the left thrust block of the dam was obtained from non-uniform analysis, which seems to have a high potential for damage during earthquakes. Observations made from damages after different earthquakes support this hypothesis. 


\section{Conclusions}

Non-uniform ground motion was generated by an approach based on rigorous seismic wave scattering analysis considering the effects of SH and SV waves and a trial and error process. The efficiency and applicability of this method is illustrated by generation of the Chino Hills 2008 earthquake at the Pacoima Dam site. Comprehensive studies were carried out to assure that the results obtained agreed with real available records.

System identification of the dynamic behavior of the Pacoima Dam during the 2008 earthquake was performed using the ARX method for calibration of the numerical model. To consider the effects of the spatial variation of ground motions on the dam response, multiple-input singleoutput models were applied instead of single-input single-output models. The frequencies of the first symmetric and anti-symmetric modes of the dam were computed as $5.45 \mathrm{~Hz}$ and $5.65 \mathrm{~Hz}$, respectively, which are in good agreement with available forced vibration test results.

Non-uniform and uniform seismic analysis of the Pacoima Dam was performed using the EACD-3D2008 software based on the generated and recorded excitations, respectively. The computed accelerations, displacements and acceleration response spectra were compared to the recorded responses. Good agreement was obtained between the computed displacement for different components under non-uniform excitation and recorded displacements. For uniform excitation the results were underestimated in comparison with the results obtained from recorded excitation.

The maximum acceleration responses were underestimated in uniform analysis and slightly overestimated in non-uniform analysis. The frequency content of the response was very well simulated in non-uniform analysis but not in uniform analysis.

For uniform excitation the maximum stresses were observed in the crown cantilever near the crest, but for non-uniform excitation the maximum stresses were concentrated at the sides and near the foundation. A stress concentration region near the left thrust block of the dam was obtained from non-uniform analysis, which indicates a high potential for damage during earthquakes.

\section{References}

[1] D.M. Boore, A study of possible ground-motion amplification at the Coyote Lake Dam, California, Bull. Seismol. Soc. Am., 94 (2004) 1327-1342.

[2] G.R. Darbe, Strong-motion records at Swiss dams, Proceedings of the 11th European Conference on Earthquake Engineering, (1998). 
[3] A.K. Chopra, J. Wang, Analysis and response of concrete arch dams including dam-waterfoundation rock interaction to spatially-varying ground motions, Report No. UCB/EERC-2008/03, Earthquake Engineering Research Center, University of California, Berkeley, California, 2008.

[4] C. Loh, T. Wu, System identification of Fei-Tsui arch dam from forced vibration and seismic response data, Earthquake Engineering, 4 (2000) 511-537.

[5] J.F. Hall, The dynamic and earthquake behavior of concrete dams: review of experimental behavior and observational evidence, Soil Dynamics and Earthquake Engineering, 7 (1988) 57-121.

[6] S. Mojtahedi, G. Fenves, Effect of contraction joint opening on Pacoima Dam in the 1994 Northridge earthquake, Report CSMIP/00-05 (OSMS 00-07), CA, Strong Motion Instrumentation Prg., 2000.

[7] S.W. Alves, Nonlinear analysis of Pacoima Dam with spatially non-uniform ground motion, Report No. EERL 2004-11, California Institute of Technology, Pasadena, CA, 2004.

[8] A. Zerva, Spatial variation of seismic ground motions: modeling and engineering applications, Taylor and Francis CRC Press, NY, 2009.

[9] C.H. Loh, Analysis of the spatial variation of seismic waves and ground movements from SMART1 array data, Earthquake Engineering and Structural Dynamics, 13 (1985) 561-581.

[10] R.S. Harichandran, E.H.Vanmarcke, Stochastic variation of earthquake ground motion in space and time, J. Eng. Mech. Div.112 (1986) 154-174.

[11] J.E. Luco, H.L. Wong, Response of a rigid foundation to a spatially random ground motion, Earthquake Engineering and Structural Dynamics, 14 (1986) 891-908.

[12] N.A. Abrahamson, Spatial variation of multiple support inputs, Proceedings of the 1st U.S. Seminar on Seismic Evaluation and Retrofit of Steel Bridges, San Francisco, CA, 1993.

[13] A. Der Kiureghian, A. Neuenhofer, Response spectrum method for multiple-support seismic excitation, Earthquake Engineering and Structural Dynamics, 21 (1992) 712-740.

[14] M. Shinozuka, G. Deodatis and T. Harada, Digital simulation of seismic ground motion, Technical Report, National Center for Earthquake Engineering Research, Vol. 87, Issue 17.

[15] H. Kawakami, H. Mogi, Simulated space time variation of earthquake ground motion including observed time history records, Proceedings of 11th WCEE, 1996, 908

[16] M. Shinozuka, G. Deodatis, R. Zhang, A. S. Papageorgiou, Modeling, synthetics and engineering applications of strong earthquake wave motion, Soil Dynamics and Earthquake Engineering, 18 (1999) 209-228.

[17] A.A. Dumanoglu, R.T. Severn, Dynamic response of dams and other structures to differential ground motions, Proc. Inst. Civ. Engs., Part 2, 77 (1984) 333-352. 
[18] A.A. Dumanoglu, R.T. Severn, C.A. Taylor, Effect ofasynchronous input on theresponse of dams, Proceedings of the 8th World Conf. on Earthquake Engineering, 6, SanFrancisco, 1984, pp. 127133.

[19] M.A. Haroun, E.A. Abdel-Hafiz, Seismic response analysis of earth dams under differential ground motion, Bul. Seism. Soc. Am., 77(5) (1987) 1514-1529.

[20] M.T. Chen, R.S. Harichandran, Response of an earth dam to spatially varying earthquake ground motion, J. Eng. Mech., 127(9) (1995), 932-939.

[21] P.Y. Bard, Seismic input motion for large structures", 18ieme Seminaire Regional Europeen de Genie Parasismique, France, 1995.

[22] A. S. Papageorgiou, D. Pei, A discrete wavenumber boundary element method for study of the 3-D response 2-D scatterers, Earthquake Engineering and Structural Dynamics, 27(6) (1998), 619-638.

[23] J. F. Semblat, Modeling seismic wave propagation and amplification in $1 \mathrm{D} / 2 \mathrm{D} / 3 \mathrm{D}$ linear and nonlinear unbounded media, Int. Journal of Geomechanics, 11, (2011) 440-448.

[24] P.S. Nowak, Effect of non-uniform seismic input on arch dams, $\mathrm{PhD}$ dissertation, Report No. EERL-88-03, California Institute of Technology, Pasadena, California, 1988.

[25] S.B. Kojic, Earthquake response of arch dams to non-uniform canyon motion, $\mathrm{PhD}$ dissertation, Southern California University, 1988.

[26] T.K Mossessian, M. Dravinski, Amplification of elastic waves by a three dimensional valley, Earthquake Engineering and Structural Dynamics, 19(5), (1990), 667-680.

[27] L. Zhang, A.K. Chopra, Three-dimensional analysis of spatially varying ground motions around a uniform canyon in a homogeneous half-space, Earthquake Engineering and Structural Dynamics, 20, (1991), 911-926.

[28] P. Dakoulas, H. Abouseeda, Response of earth dams to P and SV waves using coupled FE-BE formulation, Earthquake Engineering and Structural Dynamics, 25(11) (1996) 1177-1194.

[29] T. Szczesiak, B. Weberb, H. Bachmannb, Nonuniform earthquake input for arch dam-foundation interaction, Soil Dynamics and Earthquake Engineering, 18(7), (1999), 487-493.

[30] S. Mojtahedi, G.L.Fenves, Response of concrete arch dam in the 1994 Northridge, California earthquake, $11^{\text {th }}$ WCEE, 2000, pp. 1713-1720.

[31] O. Maeso,J.Aznarez, J. Dominguez, Effects of space distribution of excitation on seismic response of arch dams, Journal of Engineering Mechanics, 128 (2002) 759-768.

[32] S.W. Alves, J.F. Hall, Generation of spatially nonuniform ground motion for nonlinear analysis of a concrete arch dam, Earthquake Engineering and Structural Dynamics, 35(11) (2006) 1339-1357.

[33] J. Wang, A.K. Chopra, A computer program for three-dimensional analysis of concrete dams subjected to spatially-varying ground motion, Report No. UCB/EERC-2008/04, Earthquake Engineering Research Center, University of California, Berkeley, California, 2008. 
[34] R.Tarinejad, Seismic load for canyon site structures, Ph.D. thesis, Tarbiat Modares University, Tehran, Iran, 2007.

[35] R. Tarinejad, Efficient algorithm in order to generate non-uniform ground motion, Geoshanghai International Conference, Soil Dynamics and Earthquake Engineering, ASCE, Shanghai, China, 2010 .

[36] S.W Alves, J.F. Hall, System identification of a concrete arch dam and the calibration of its finite element model, Earthquake Engineering and Structural Dynamics, 35(11) (2006) 1321-1337.

[37] R. Tarinejad, R. Fatehi, Modal identification of an arch dam during various earthquakes, Proceedings of the 1st International Conference on Dams and Hydropower, Tehran, Iran, 2012. 

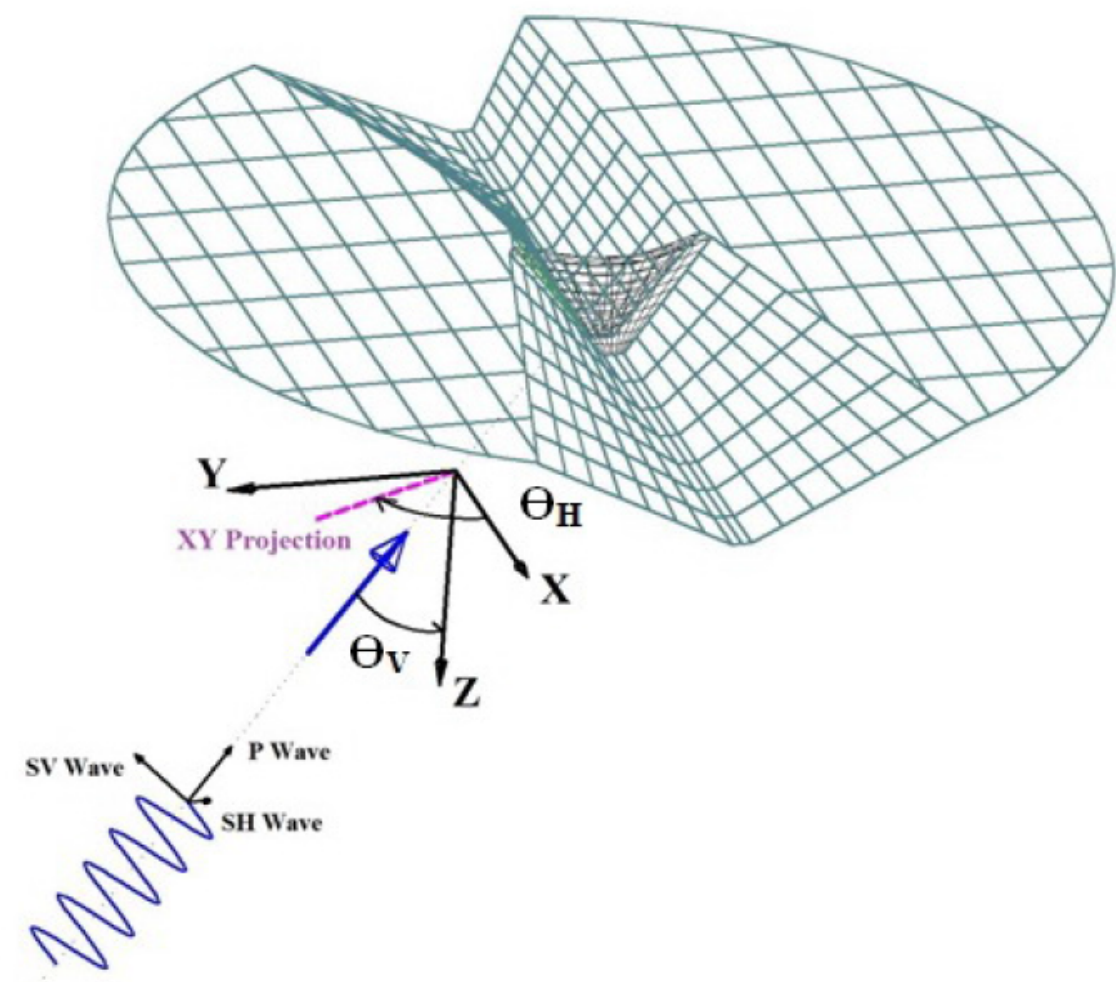

Source

Figure 1: Definition of incident seismic wave angles $\theta_{h}$ and $\theta_{v}$ corresponding to the direction of the normal to the wave front with the horizontal $x$ - and the vertical $z$-axes, respectively 
Pacoima Reservoir - Pacoima Dam

(CSMIP Station No. 24207)

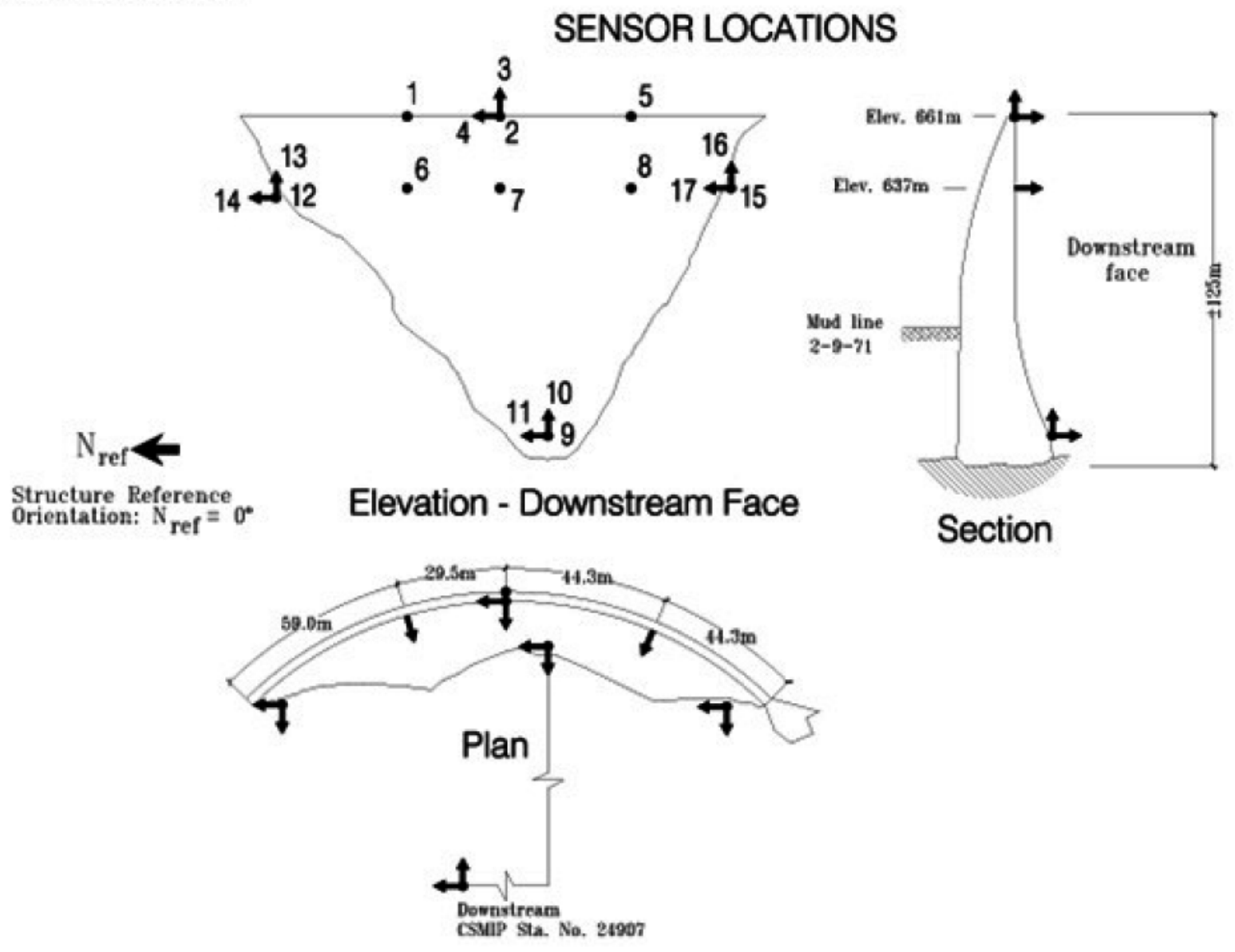

Figure 2: Accelerometer locations at the Pacoima Dam including their direction and reference number [http://www.strongmotioncenter.org/NCESMD/photos/CGS/1llayouts/1124207.gif] 
CISN ShakeMap : 4.0 mi SE of Diamond Bar, CA

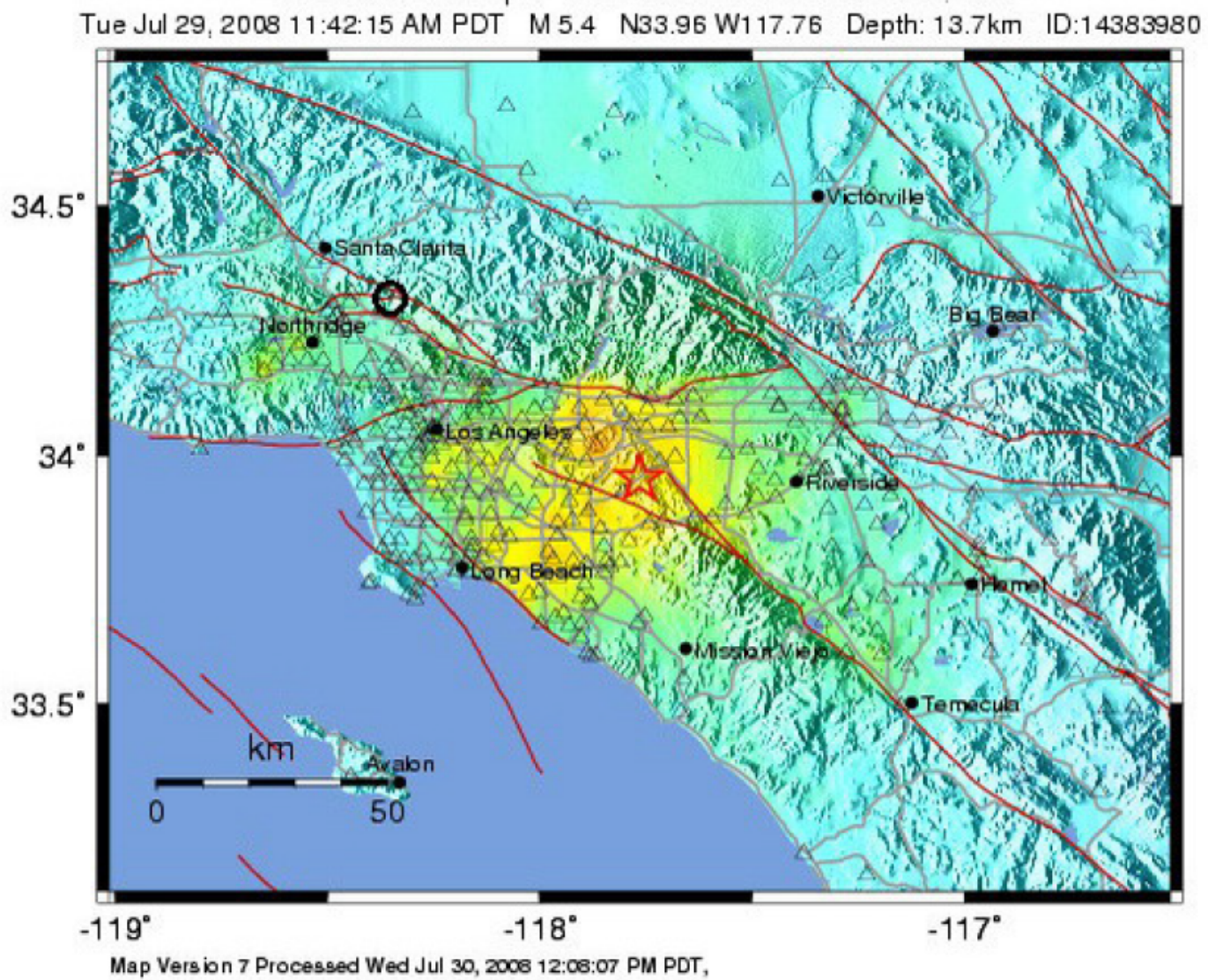

\begin{tabular}{|c|c|c|c|c|c|c|c|c|c|}
\hline $\begin{array}{l}\text { PEPCENVED } \\
\text { SHAKING }\end{array}$ & Not telt & Weak & Light & Moderate & Strong & Very strong & Severe & Violent & Extreme \\
\hline $\begin{array}{l}\text { POTENTIAL } \\
\text { DAMAGE }\end{array}$ & none & none & none & Very ight & Light & Moderate & Moderale/Heavy & Heavy & Very Heavy \\
\hline PEAK AOC $(\%)$ & $<.17$ & $.17-1.4$ & $1.4-3.9$ & $3.9-9.2$ & $9.2-18$ & $18-34$ & $34-65$ & $65-124$ & $>124$ \\
\hline PEAK VEL $(\mathrm{cm} / \mathrm{s})$ & $<0.1$ & $0.1-1.1$ & $1.1-3.4$ & $3.4-8.1$ & $8.1-16$ & $16-31$ & $31-60$ & $60-116$ & $>116$ \\
\hline $\begin{array}{l}\text { INSTRUMENTAL } \\
\text { IWIENSITY }\end{array}$ & I & IH-III & IV & V & VI & VII & VIII & IX & $X_{t}$ \\
\hline
\end{tabular}

Figure 3: Geographic location of epicenter of the 2008 Chino Hills earthquake (star) and Pacoima Dam (circle)[USGS.com] 


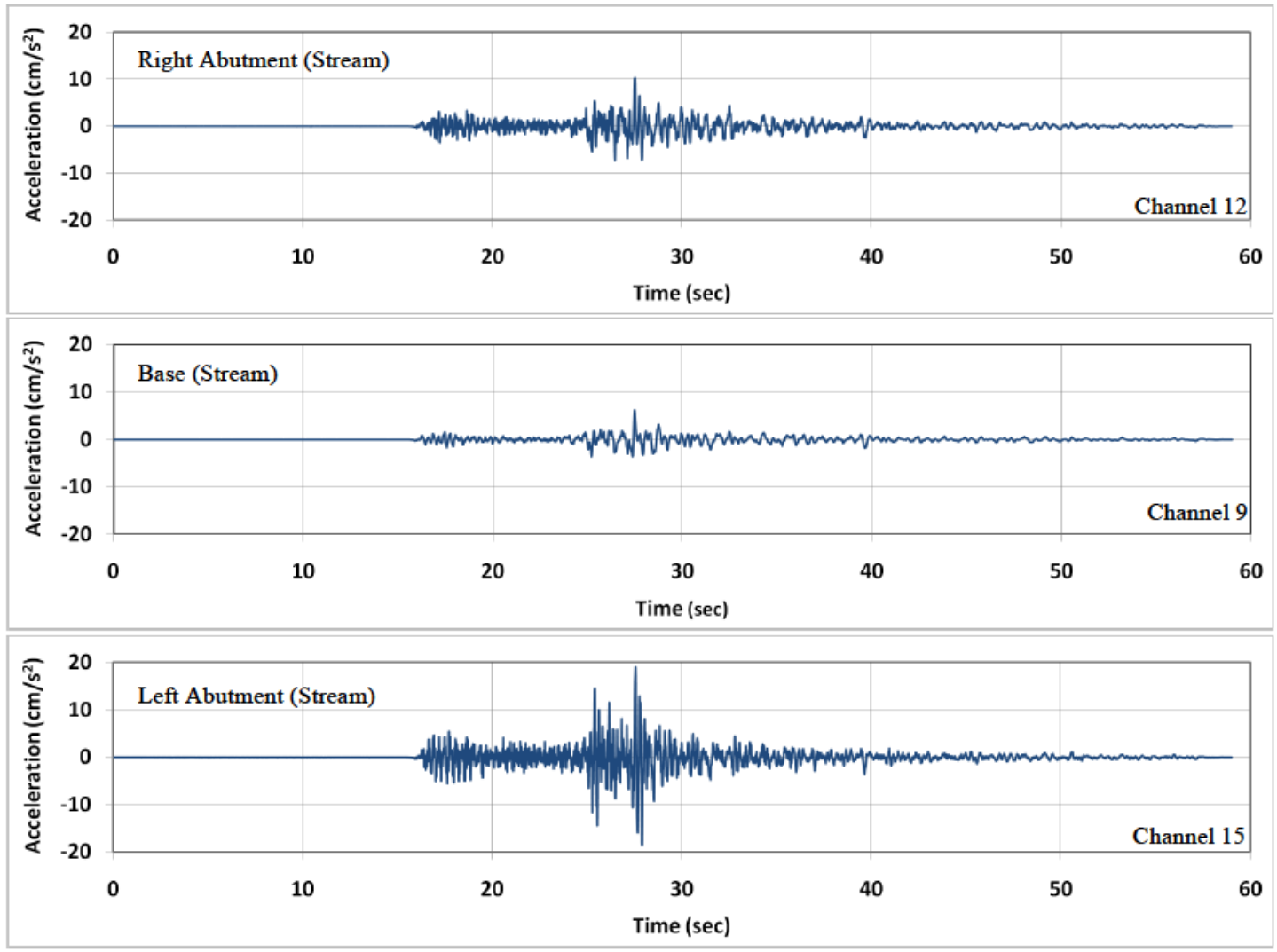

Figure 4: Recorded stream direction accelerations at the base and abutments of the Pacoima Dam during the 2008 earthquake 


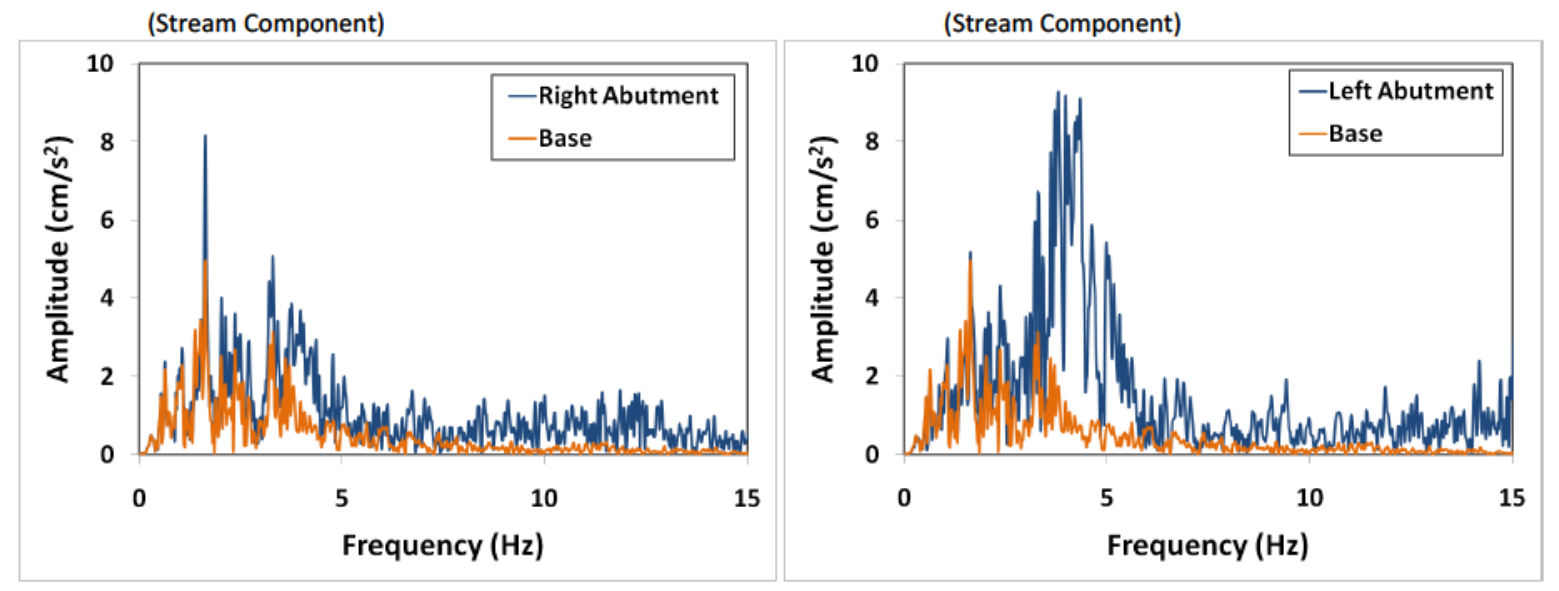

Figure 5: Comparison between the Fourier transforms of stream direction accelerations at the abutments and base of the Pacoima Dam during the 2008 earthquake 

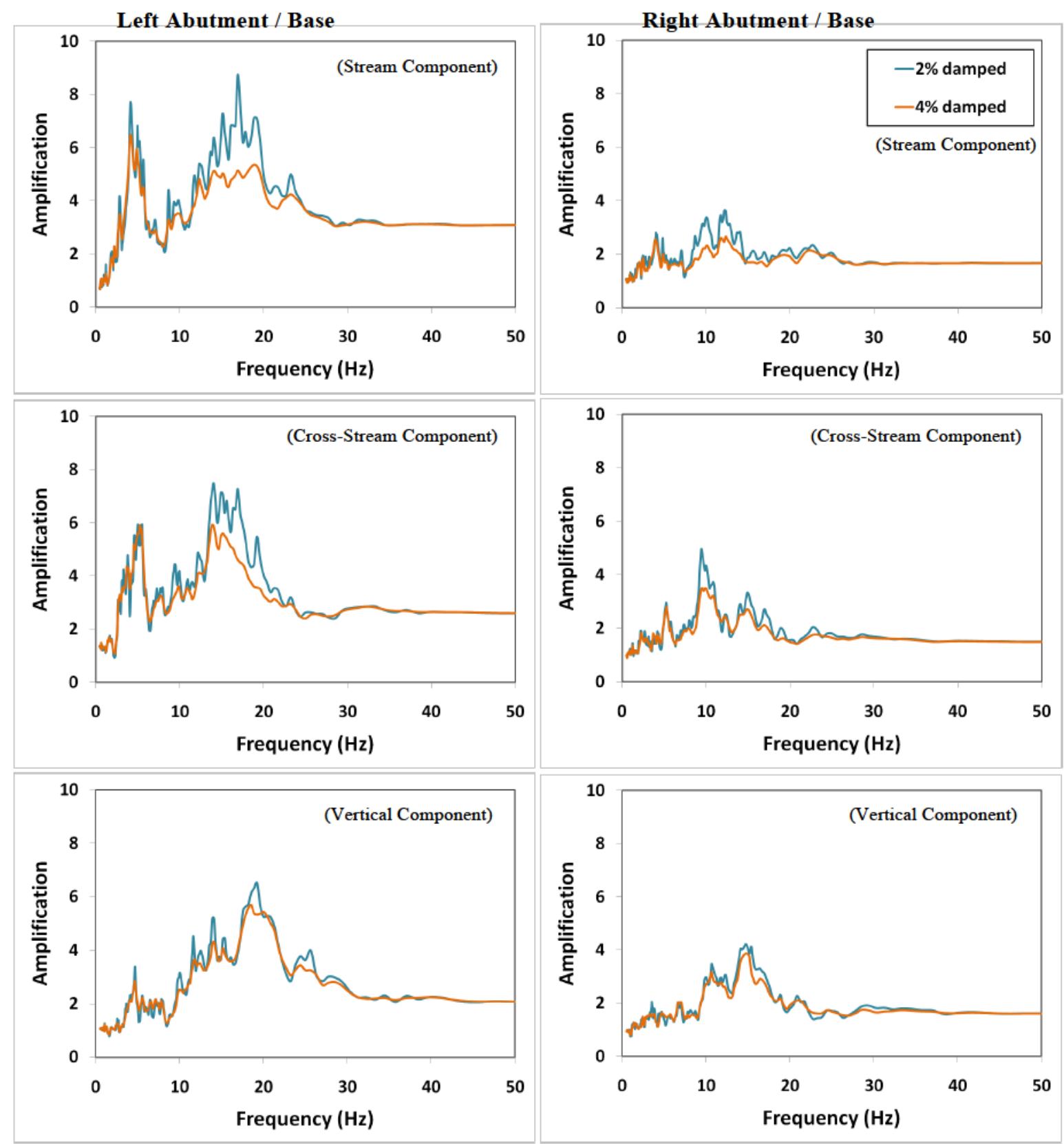

Figure 6: Response spectral ratio of recorded accelerations at the abutments and the base during the 2008 earthquake (damping ratio of $2 \%$ and $4 \%$ ) 

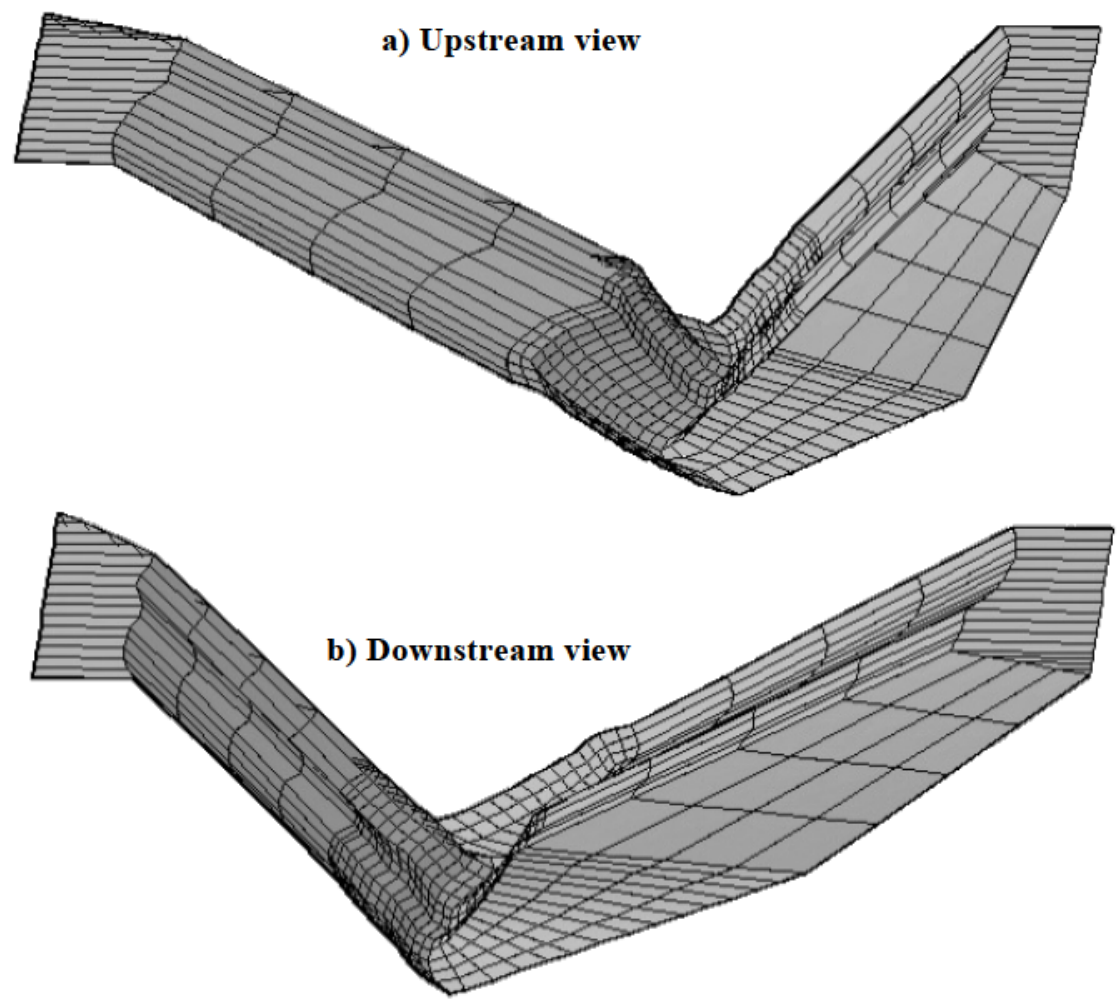

Figure 7: Boundary element model of the Pacoima Dam site: a) upstream view, and b) downstream view 


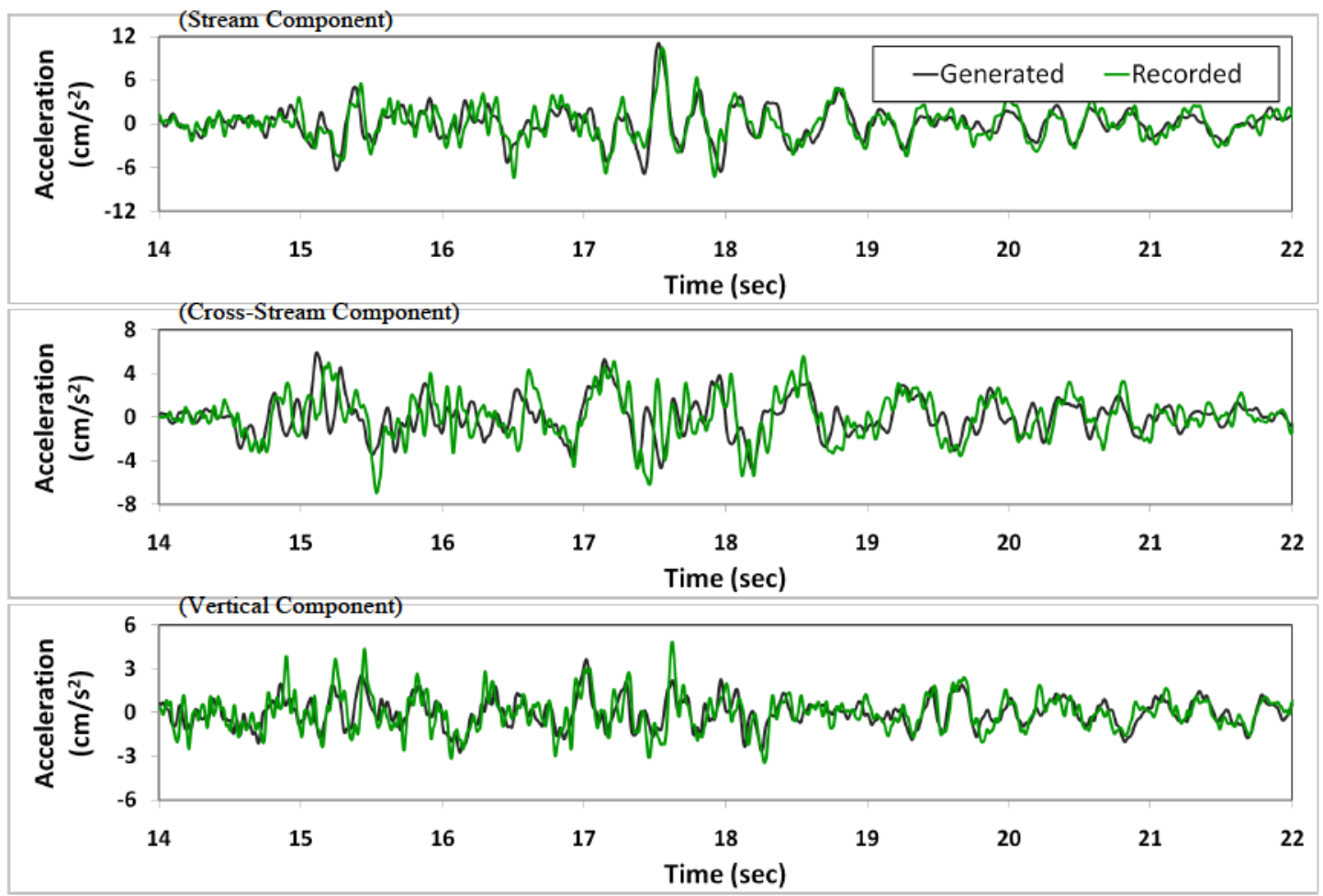

Figure 8: Agreement of the generated acceleration time series with corresponding records at the right abutment 

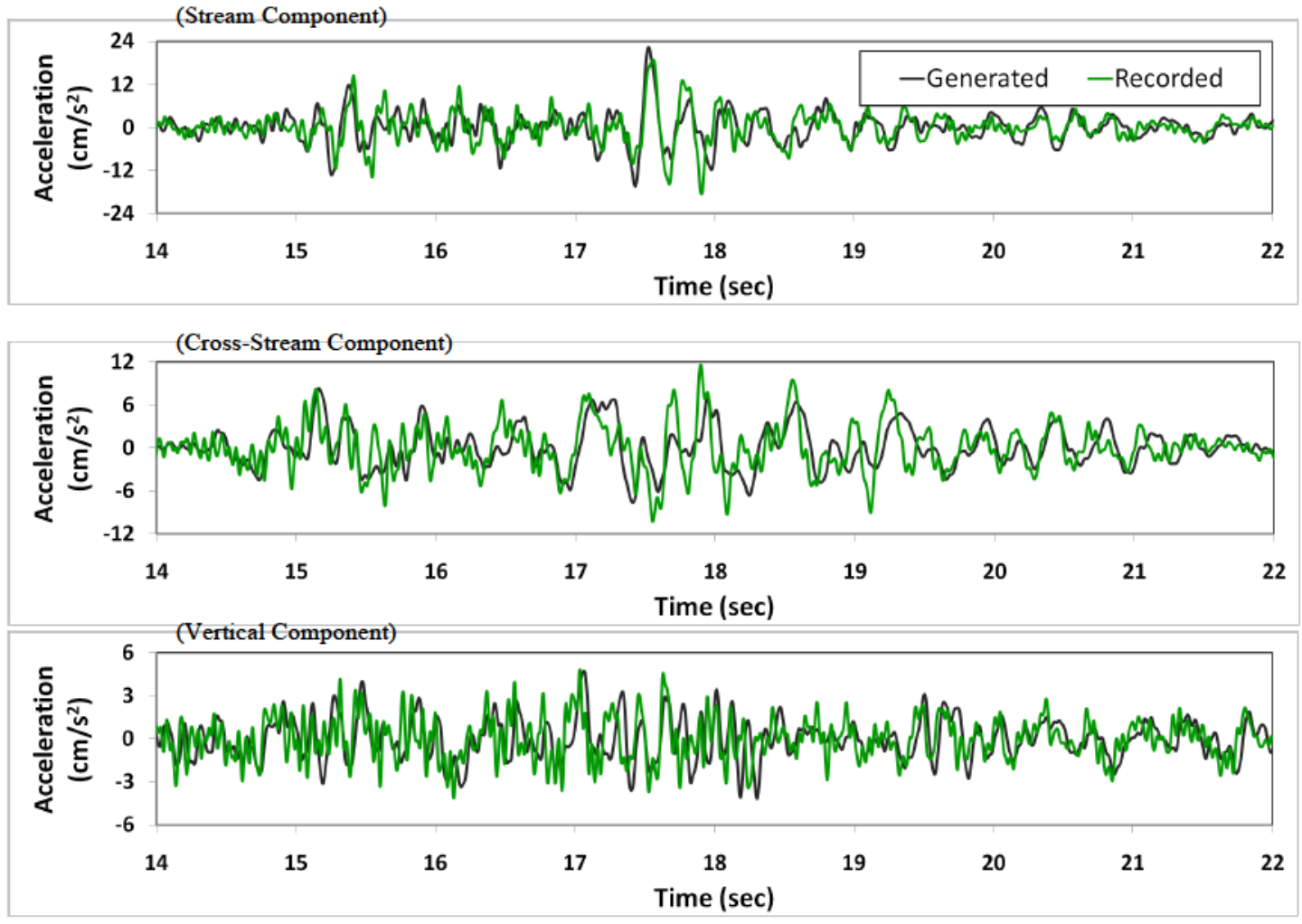

Figure 9: Agreement of the generated acceleration time series with corresponding records at the left abutment 

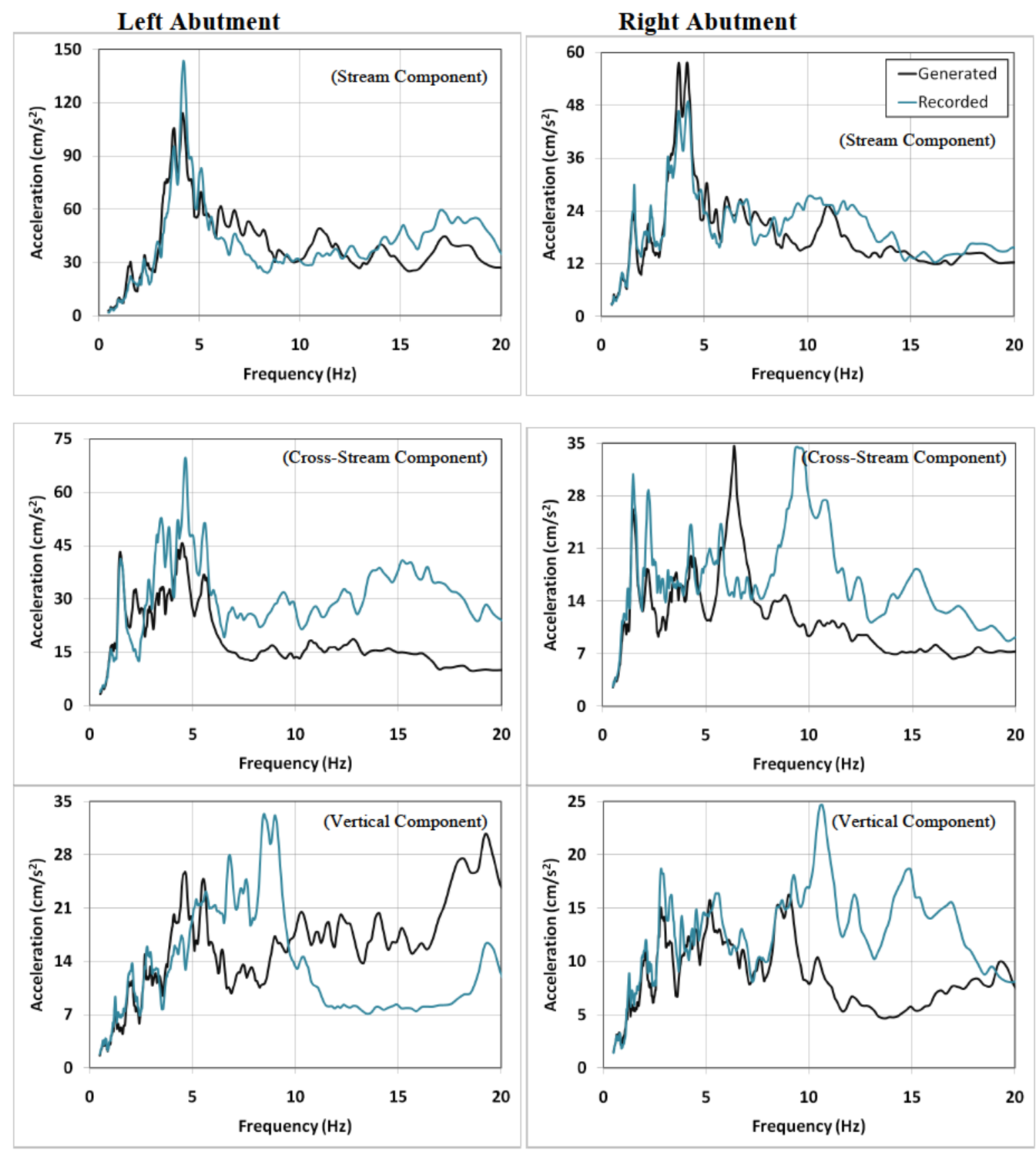

Figure 10: $2 \%$ damped acceleration response spectrum of generated and recorded accelerations during the 2008 earthquake at abutments of the Pacoima Dam 


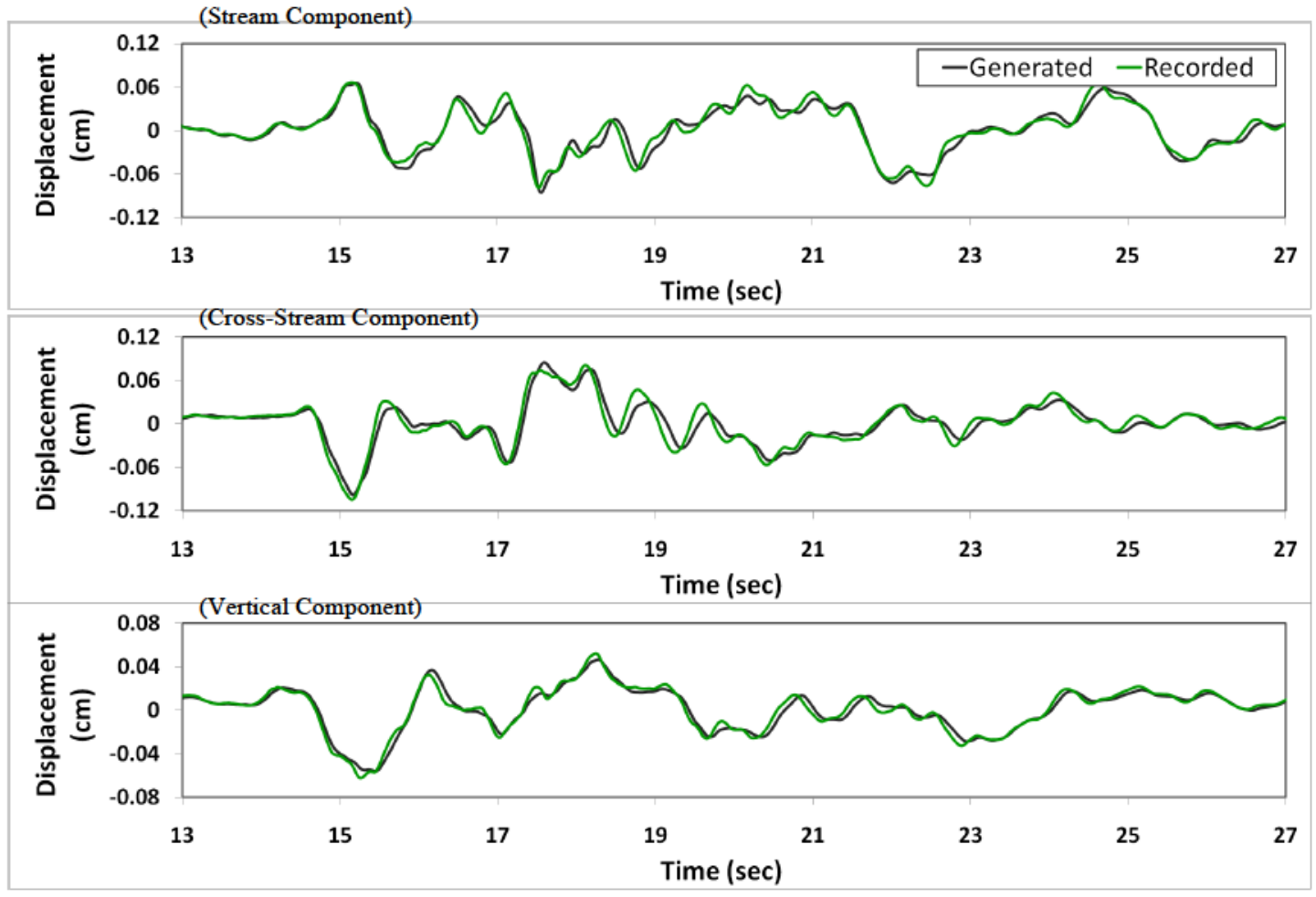

Figure 11: Agreement of the generated displacement time series with estimated displacements at the right abutment 

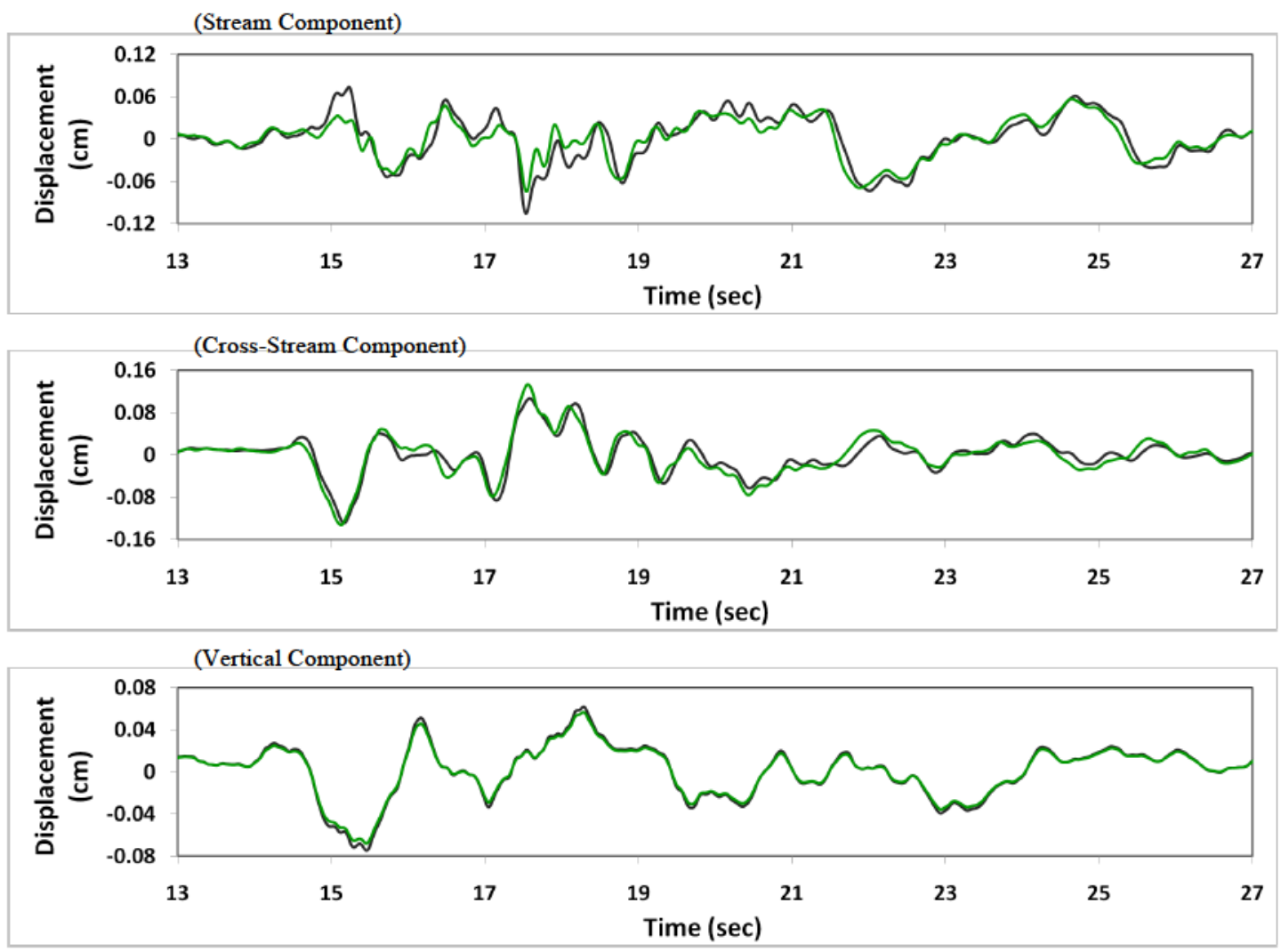

Figure 12: Agreement of the generated displacement time series with estimated displacements at the left abutment 


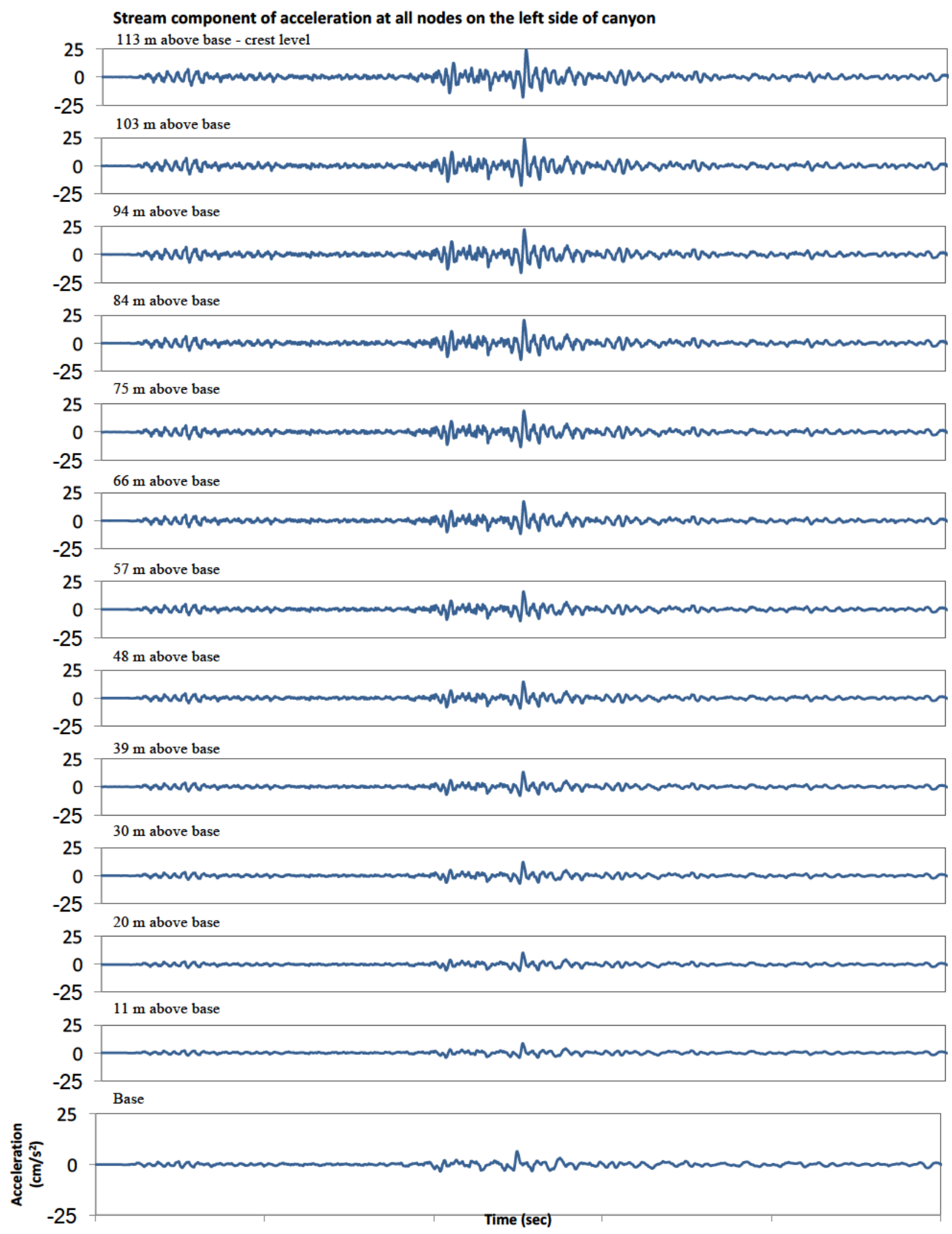

Figure 13: Stream components of accelerations along the left abutment of the Pacoima Dam canyon 


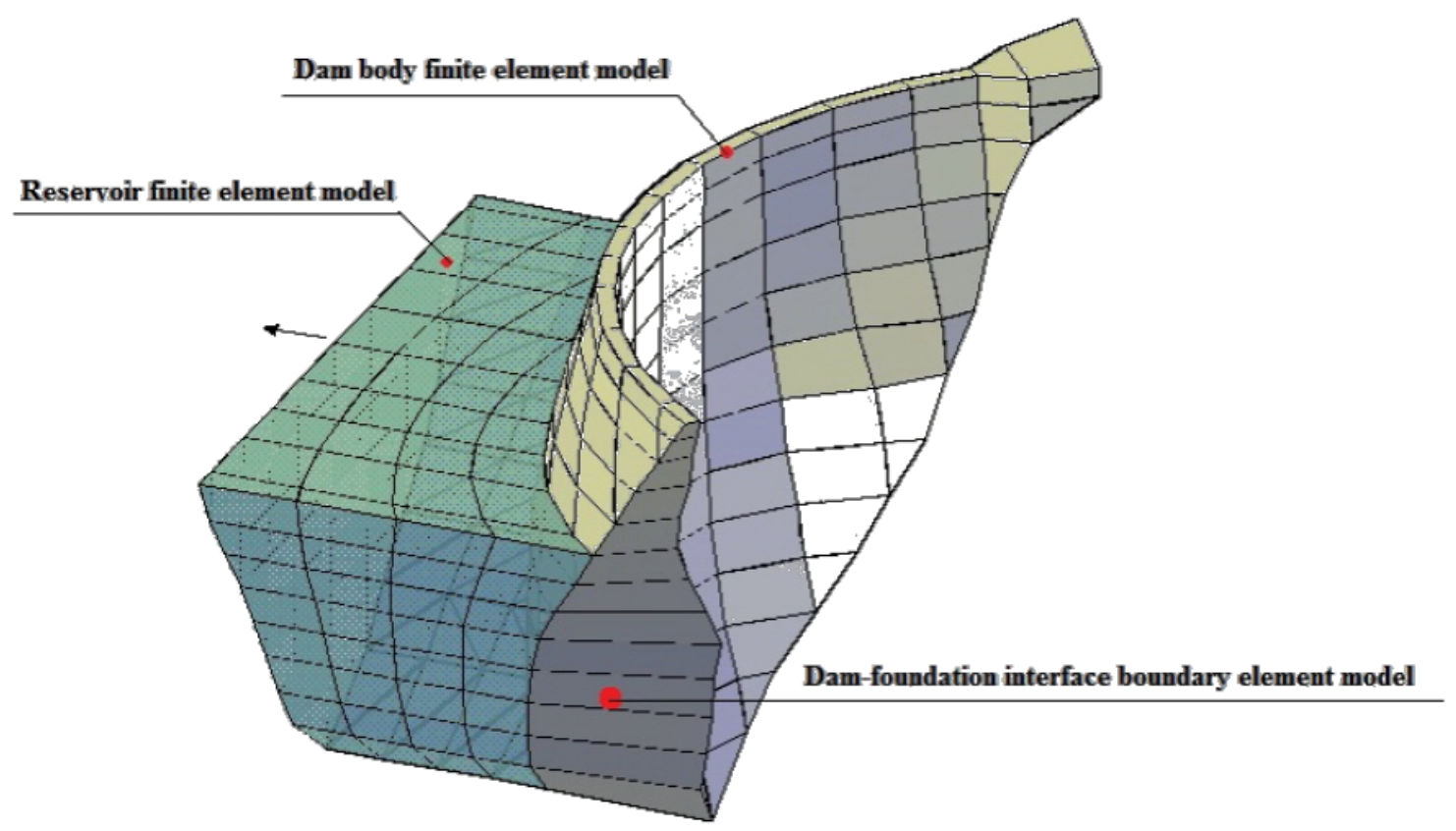

Figure 14: Finite element model of the Pacoima Dam-foundation-reservoir system 


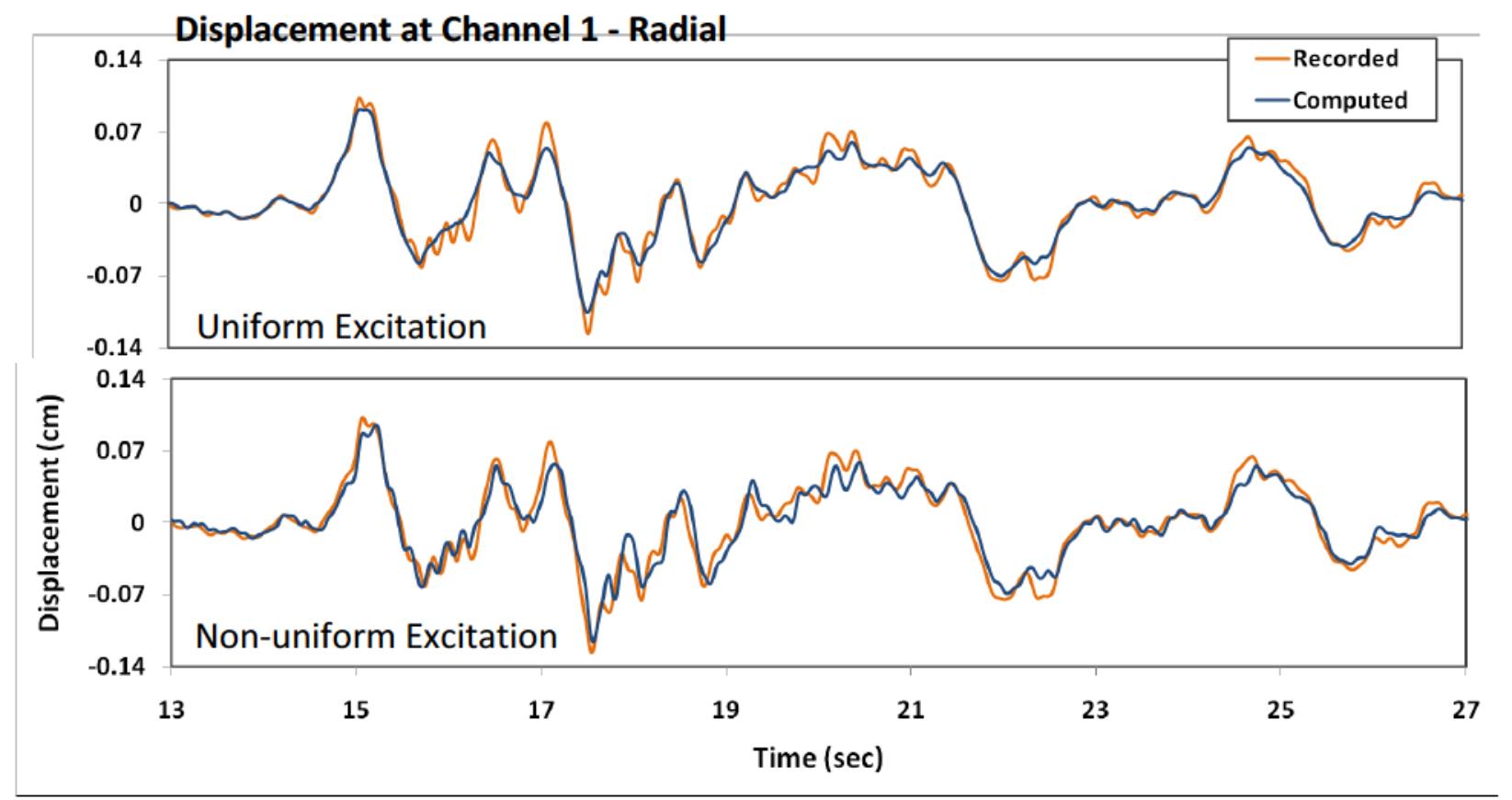

Figure 15: Recorded and computed displacements at Channel 1 


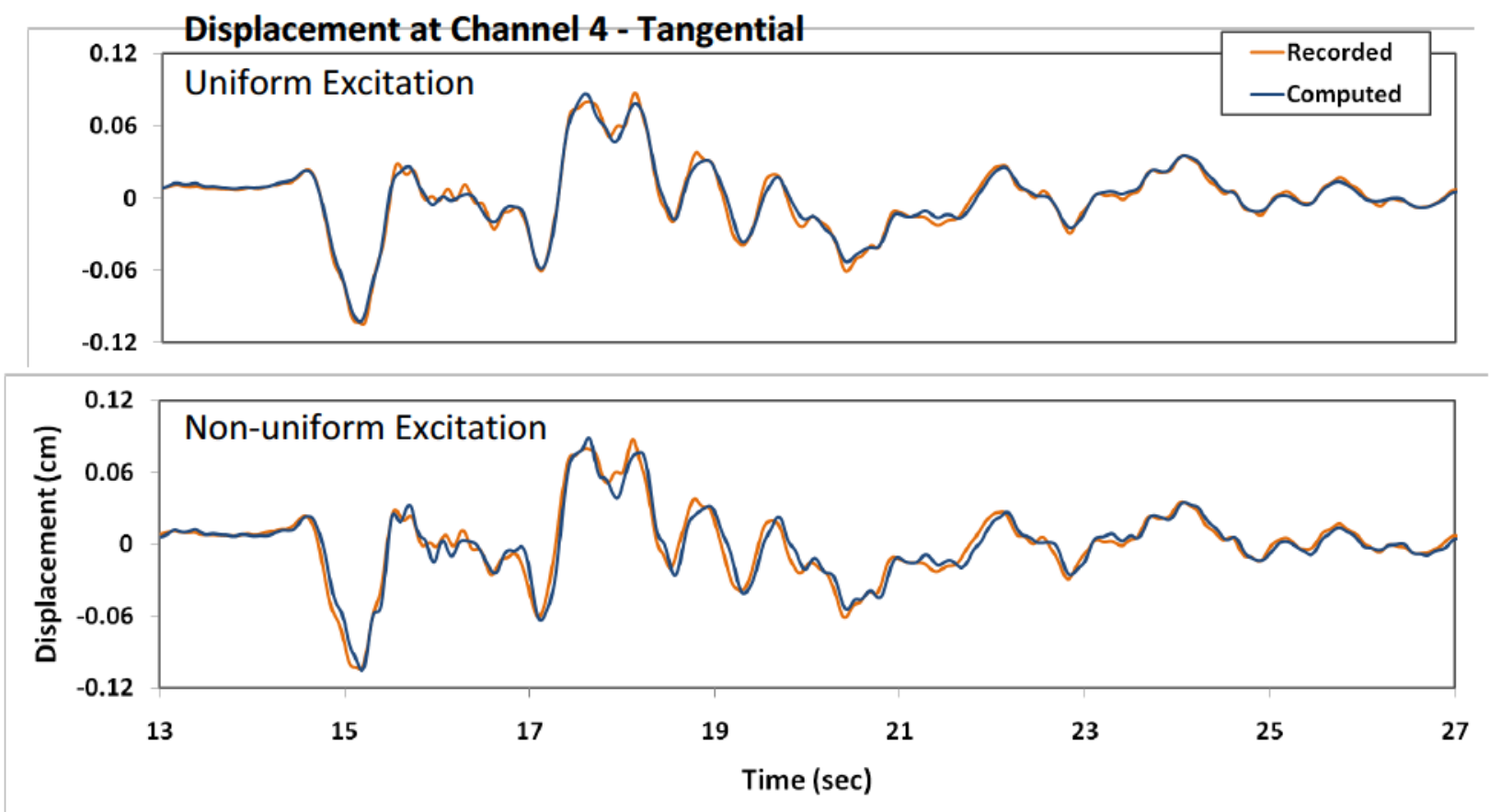

Figure 16: Recorded and computed displacements at Channel 4 


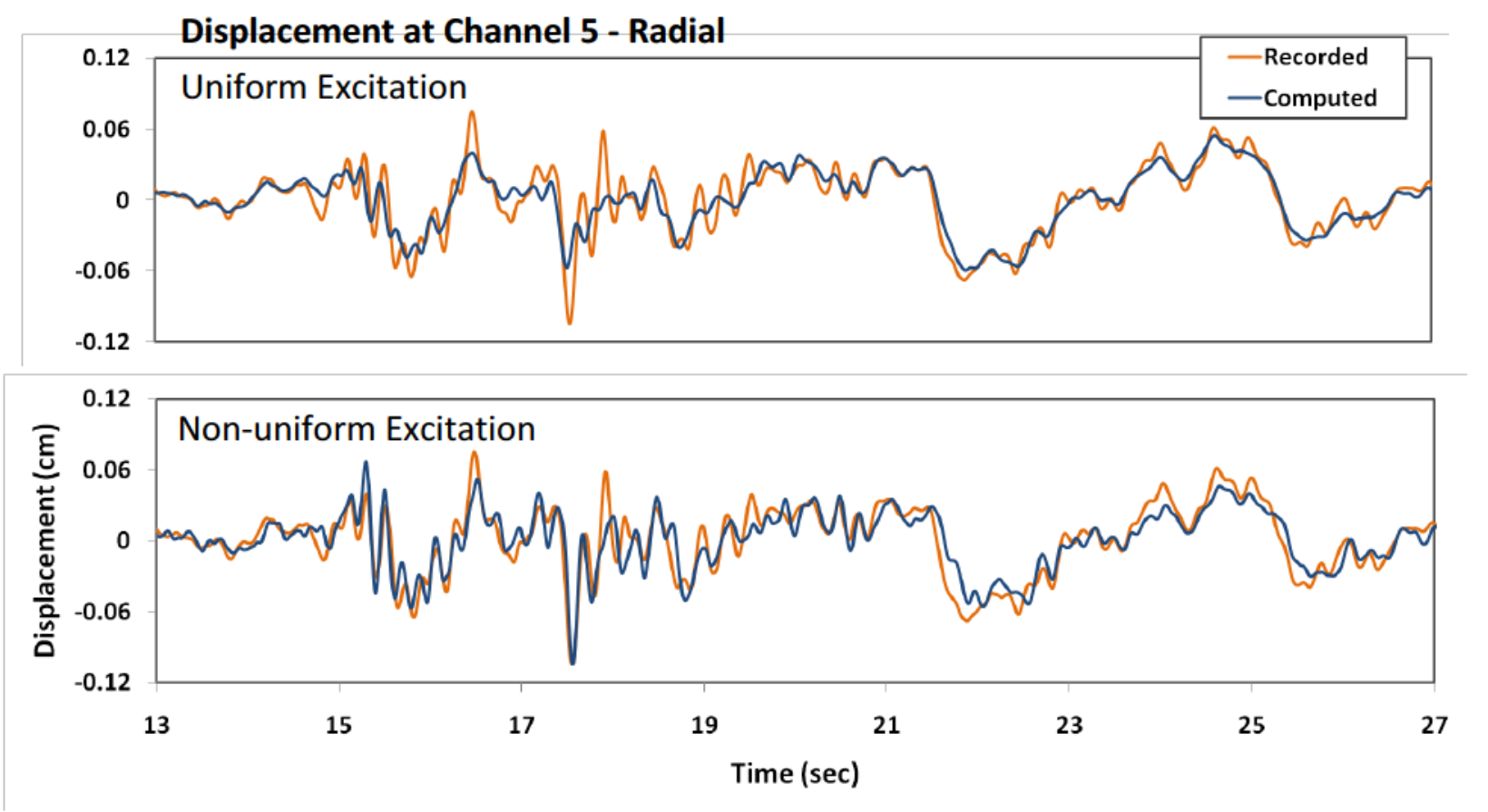

Figure 17: Recorded and computed displacements at Channel 5 


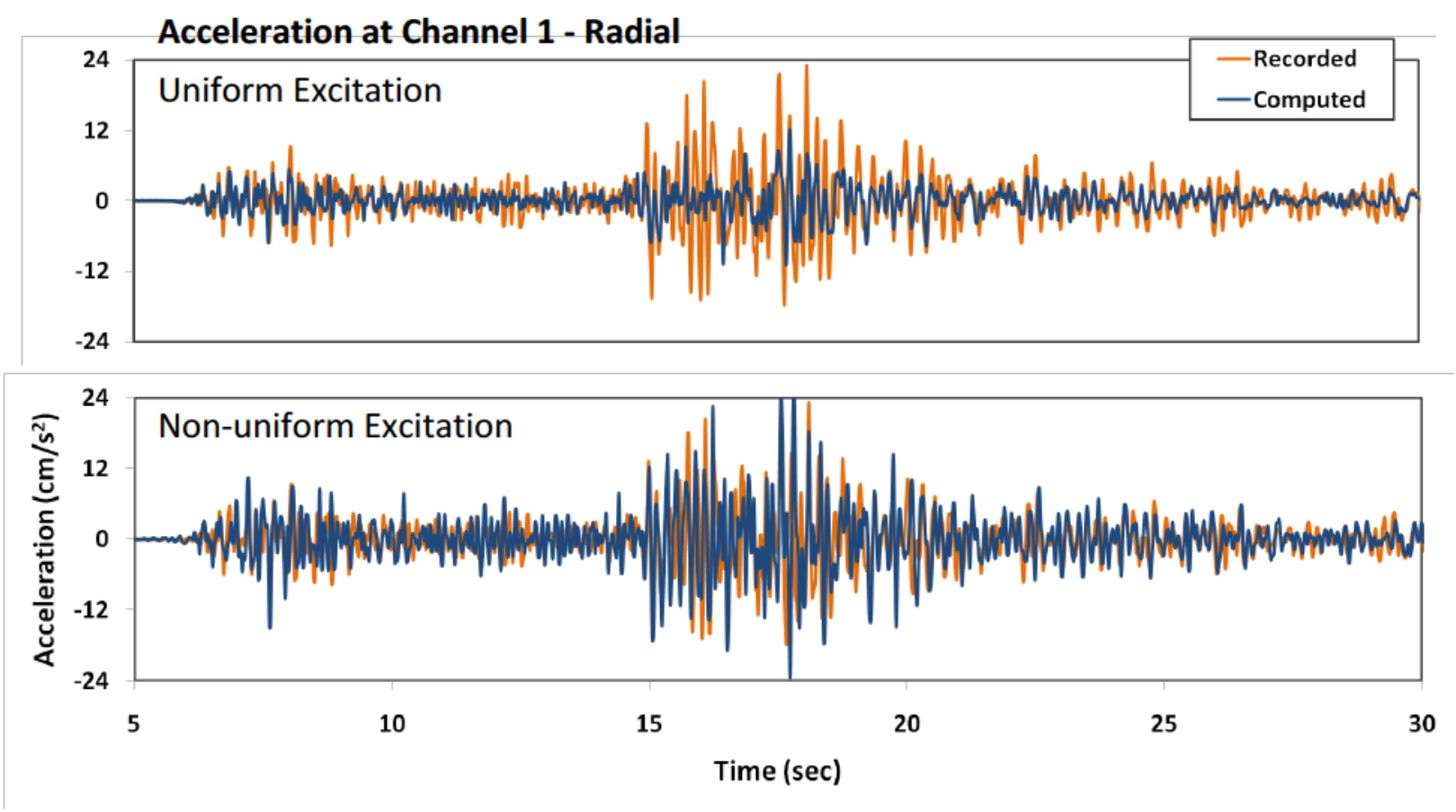

Figure 18: Recorded and computed accelerations at Channel 1 

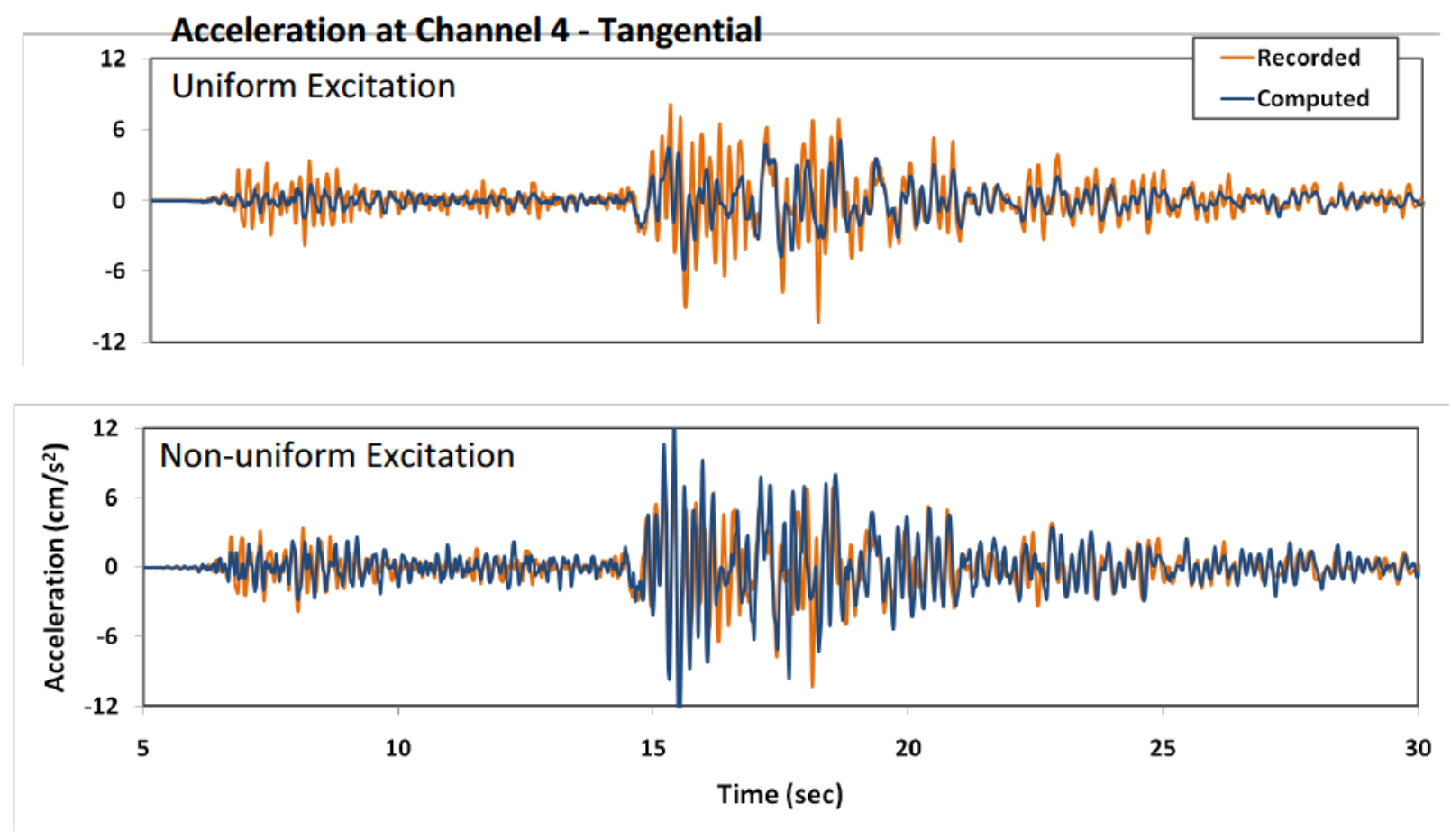

Figure 19: Recorded and computed accelerations at Channel 4 


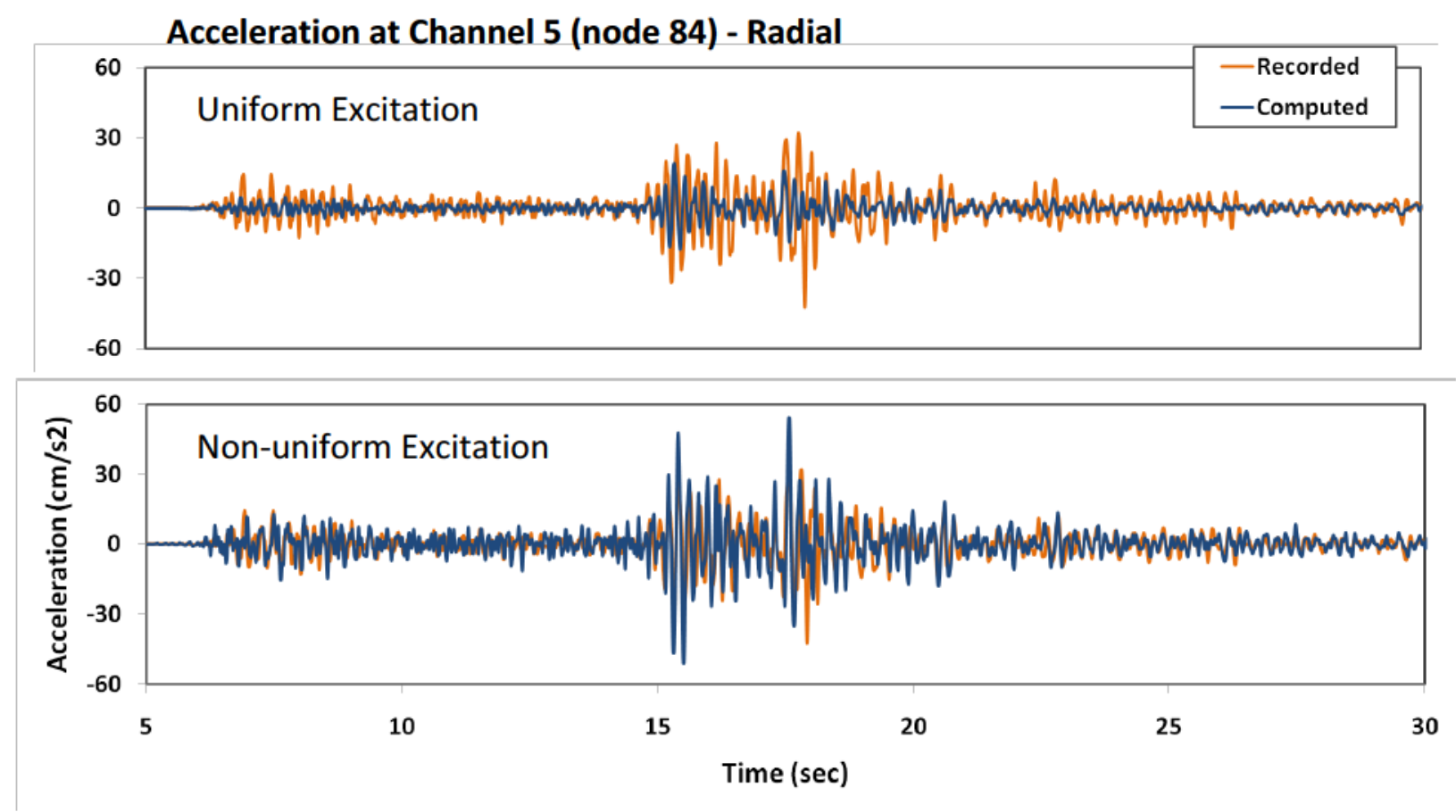

Figure 20: Recorded and computed accelerations at Channel 5 


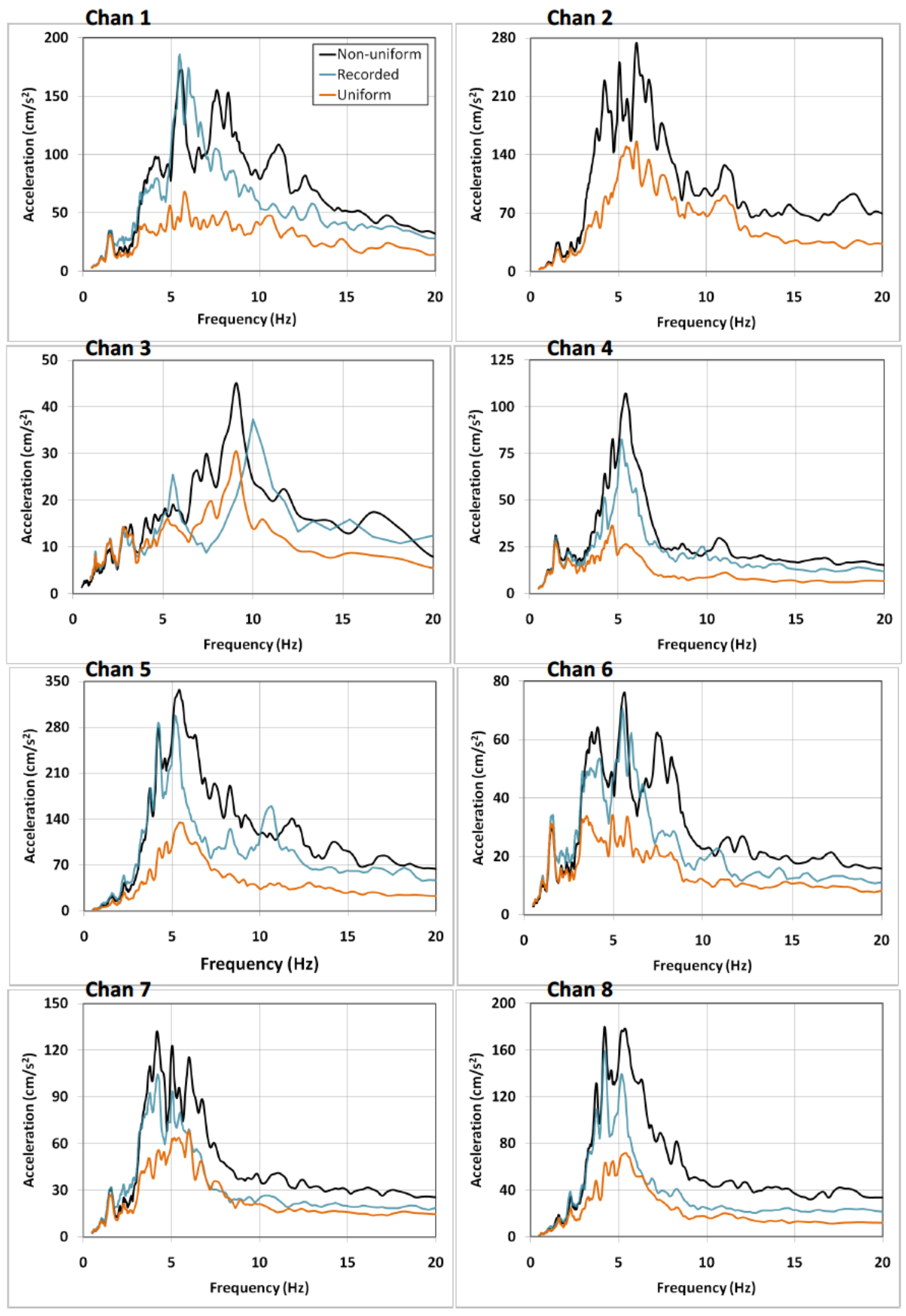

Figure 21: 2\% damped response spectra of recorded and computed accelerations obtained from uniform and non-uniform analysis 

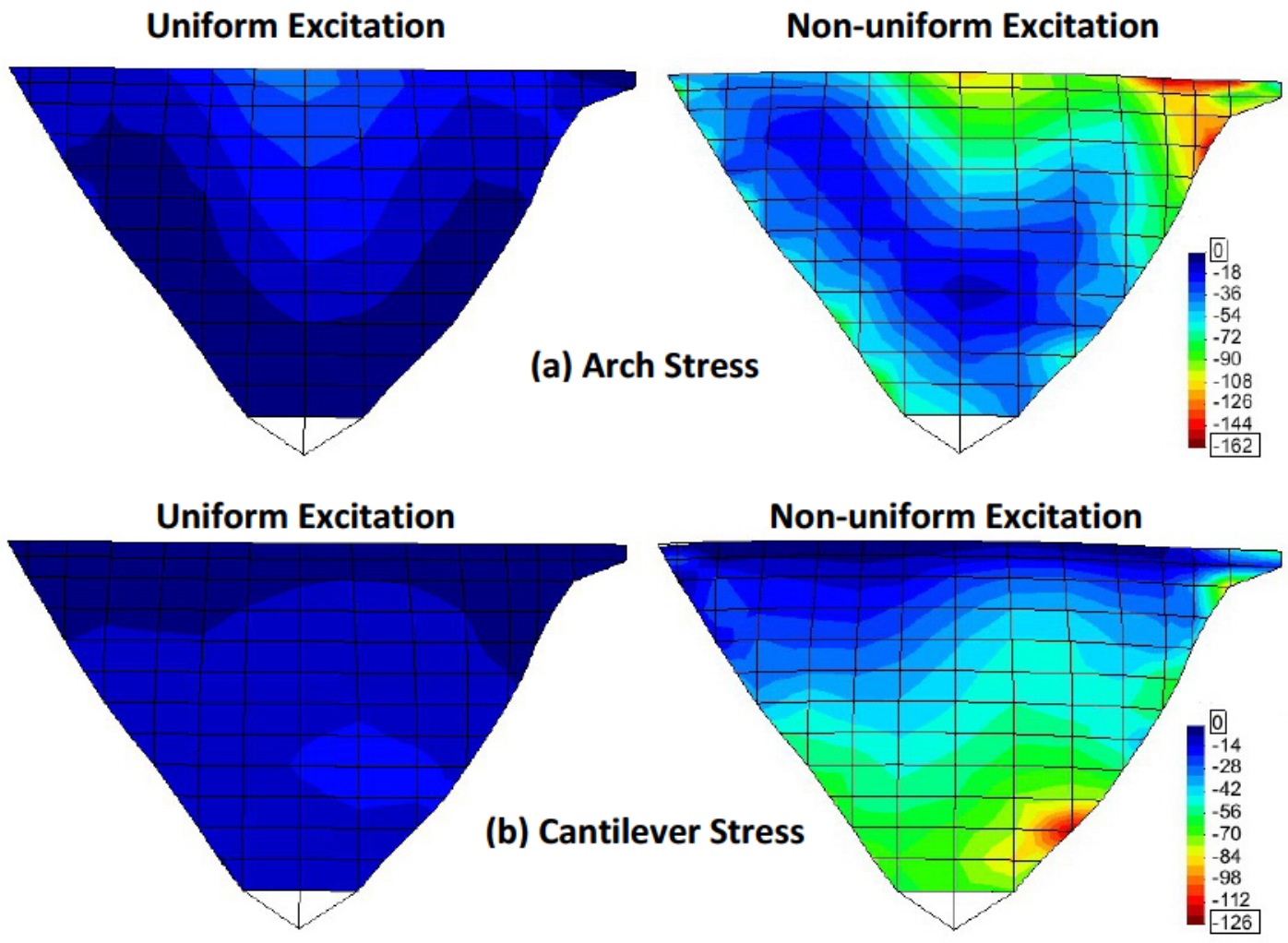

Figure 22: Envelope of the tensile arch and cantilever stresses $(\mathrm{kPa})$ on the upstream face of the dam due to uniform and non-uniform excitations 


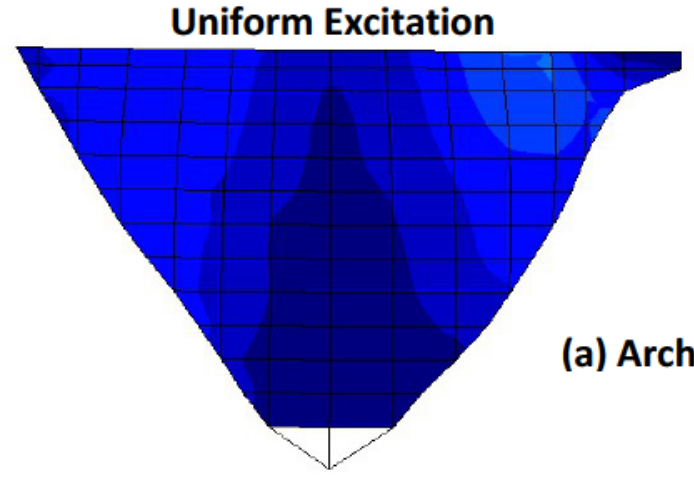

\section{Uniform Excitation}

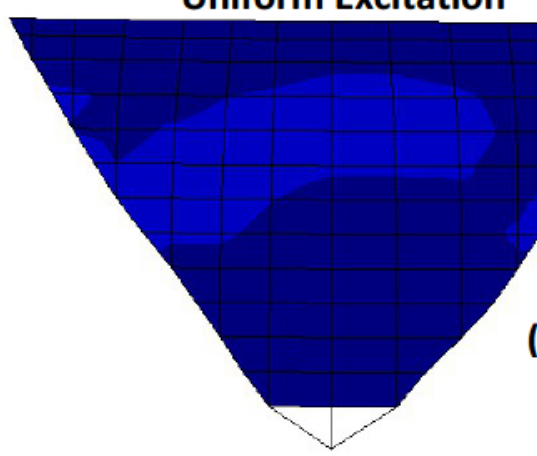

(b) Cantilever Stress
Non-uniform Excitation

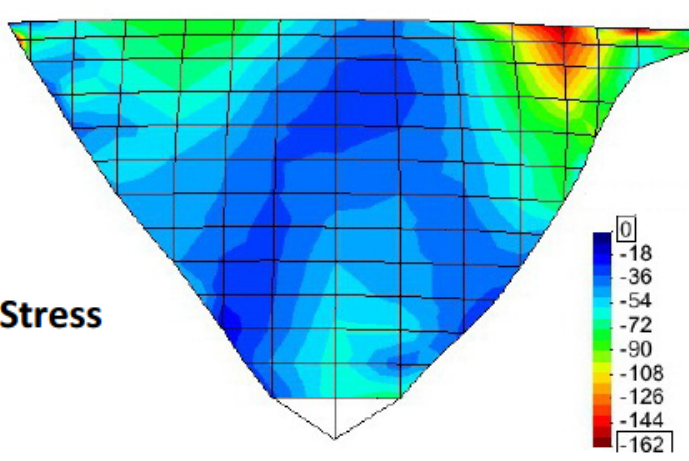

Non-uniform Excitation

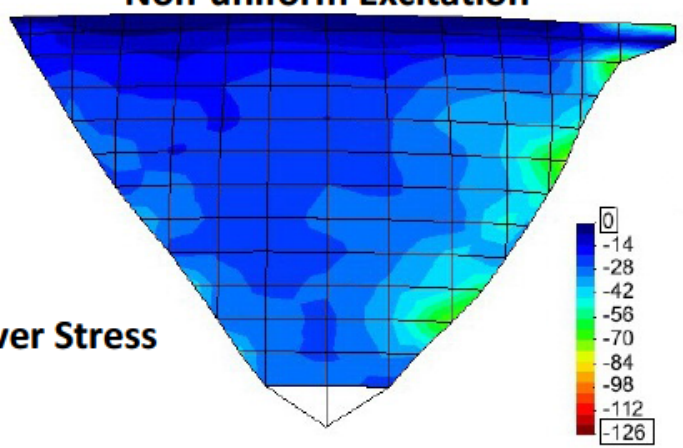

Figure 23: Envelope of the tensile arch and cantilever stresses $(\mathrm{kPa})$ on the downstream face of the dam due to uniform and non-uniform excitations 